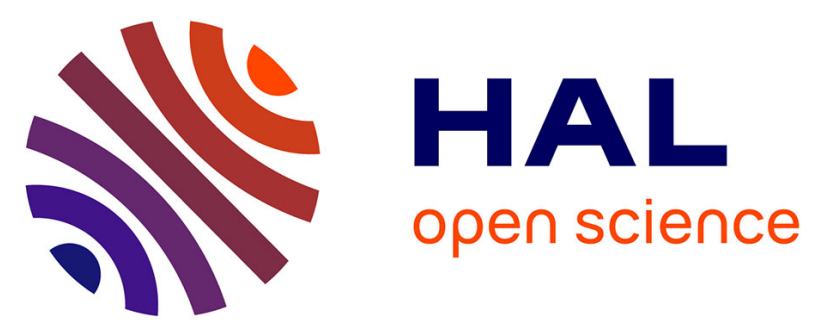

\title{
Activation of C-H Bond of Propane by Strong Basic Sites Generated by Bulk Proton Conduction on V-Modified Hydroxyapatites for the Formation of Propene
}

Sarah Petit, Cyril Thomas, Yannick Millot, Jean-Marc Krafft, Christel

Laberty-Robert, Guylène Costentin

\section{To cite this version:}

Sarah Petit, Cyril Thomas, Yannick Millot, Jean-Marc Krafft, Christel Laberty-Robert, et al.. Activation of C-H Bond of Propane by Strong Basic Sites Generated by Bulk Proton Conduction on V-Modified Hydroxyapatites for the Formation of Propene. ChemCatChem, In press, 10.1002/cctc.201902181 . hal-02503822

\section{HAL Id: hal-02503822 \\ https://hal.sorbonne-universite.fr/hal-02503822}

Submitted on 10 Mar 2020

HAL is a multi-disciplinary open access archive for the deposit and dissemination of scientific research documents, whether they are published or not. The documents may come from teaching and research institutions in France or abroad, or from public or private research centers.
L'archive ouverte pluridisciplinaire HAL, est destinée au dépôt et à la diffusion de documents scientifiques de niveau recherche, publiés ou non, émanant des établissements d'enseignement et de recherche français ou étrangers, des laboratoires publics ou privés. 


\section{Activation of C-H Bond of Propane by Strong Basic Sites Generated by Bulk Proton Conduction on V-Modified Hydroxyapatites for the Formation of Propene.}

Sarah Petit, ${ }^{[a, b]}$ Cyril Thomas, ${ }^{[a]}$ Yannick Millot, ${ }^{[a]}$ Jean-Marc Krafft, ${ }^{[a]}$ Christel LabertyRobert, Guylène Costentin*[a]

[a] Sorbonne Université, CNRS, Laboratoire Réactivité de Surface, LRS, F-75005 Paris, France E-mail: guylene.costentin@upmc.fr

[b] Sorbonne Université, CNRS, Laboratoire Chimie de la Matière Condensée de Paris, LCMCP, F75005 Paris, France 
Abstract: Insights into the catalytic transformation of propane to propene on V-apatites catalysts are provided based on structure-reactivity relationships. Substitution of phosphates by vanadates in the hydroxyapatite structure leads to the formation of $\mathrm{Ca}_{10}\left(\mathrm{PO}_{4}\right)_{6-x}\left(\mathrm{VO}_{4}\right)_{x}(\mathrm{OH})_{2-y} \mathrm{O}_{y} \mathrm{~V}$-oxy-hydroxy-apatite solid solutions $(x=0 \rightarrow 6)$. Bulk vanadium incorporation promotes (i) calcium rich terminations (XPS, $\mathrm{CO}$ adsorption), (ii) proton deficiency inside the $\mathrm{OH}^{-}$channels $\left({ }^{1} \mathrm{H} N M R\right.$ ) giving rise to $\mathrm{O}^{2-}$ native species, (iii) the thermally-activated formation of additional $\mathrm{O}^{2-}$ species along the $\mathrm{OH}^{-}$channels resulting in $\mathrm{H}$ bonding interaction (in situ DRIFT) and (iv) the proton conduction process that eventually results in the surface exposure of $\mathrm{O}^{2-}$ species (in situ impedance spectroscopy). The exposure of $\mathrm{Ca}^{2+}-\mathrm{O}^{2-}$ surface acidbase pairs allows the dissociation of hydrogen, emphasizing the strong basicity of the related $\mathrm{O}^{2-}$ species. Whereas an increasing vanadium content is beneficial to propene selectivity, it scarcely impacts propane conversion. The reaction proceeds mainly upon oxidative dehydrogenation, even if the minor dehydrogenation route is also observed. Surface $\mathrm{O}^{2-}$ generated thanks to proton mobility are involved in the $\mathrm{C}-\mathrm{H}$ bond activation, as shown by the synergistic effect between the oxidative dehydrogenation of propane reaction and the bulk proton conduction measured under operando conditions. This puts emphasis on the key role of strong basic sites for propane activation. 


\section{Introduction}

With a generic $\mathrm{Ca}_{10}\left(\mathrm{PO}_{4}\right)_{6}(\mathrm{OH})_{2}$ formula, hydroxyapatite $(\mathrm{HAp})$ is a calcium phosphate material exhibiting a hexagonal crystal structure (space group $\mathrm{PG}_{3} / \mathrm{m}$ ) built up from phosphate $\left(\mathrm{PO}_{4}{ }^{3-}\right)$ tetrahedra surrounded by calcium cations $\left(\mathrm{Ca}^{2+}\right)$ and resulting in the formation of channels along the c-axis into which hydroxyl groups $\left(\mathrm{OH}^{-}\right)$are stacked. ${ }^{[1]}$ Interestingly, this 3D-framework is flexible enough to accommodate the incorporation of various cations and anions substituting the $\mathrm{Ca}^{2+}$ and the $\left(\mathrm{PO}_{4}\right)^{3-}-\mathrm{OH}^{-}$sites, respectively. ${ }^{[2]}$ This peculiarity allows a wide modulation of the composition of HAps that is responsible for the numerous applications of the modified HAps that can be found in the biomedical, the physical and the chemical fields. Being the main mineral component of bones and teeth, carbonated HAps, potentially modified by $\mathrm{Mg}^{2+}$ or $\mathrm{Zn}^{2+}$ cations, ${ }^{[3]}$ have been extensively studied for bones tissue engineering, ${ }^{[4]}$ drug delivery ${ }^{[3,5]}$ or optical imaging. ${ }^{[6]}$ The HAp composition is associated with the formation of defects in the $\mathrm{OH}$ channels that are responsible for the peculiar anisotropic ionic conduction properties of this system. ${ }^{[2 h, 2 i, 7]}$ HAps are also of great interest for environmental concerns, especially for the irreversible capture of heavy metals present in waste waters, ${ }^{\left[{ }^{[8]}\right.}$ as well as in industrial waste gases. ${ }^{[9]}$ Metal-modified HAps have also been reported as efficient bi-functional heterogeneous catalysts in the fields of depollution, ${ }^{[10]}$ the valorization of biosourced alcohols ${ }^{[11]}$ and the production of chemical intermediates for the synthesis of compounds of high-added value. ${ }^{[2 f, 12]}$

In particular, vanadium-modified HAps have been found of interest for C-C bond-coupling reactions, ${ }^{[12 b,}$ ${ }^{12 c]}$ and in the oxidation of numerous alcohols and alkanes. ${ }^{[2 f, 12 a, 12 d-h]}$ In the context of the increasing gap between the production and the demand in propene on the world market, the catalytic oxidative dehydrogenation of propane (ODHP) reaction has been recently the subject of a renewed interest. ${ }^{[13]}$ HAps have been reported as a promising system for ODHP. ${ }^{[2 f]}$ Over such catalytic materials, Sugiyama and Hayashi assumed that an "oxygen species", derived from the abstraction of a hydrogen atom of a hydroxyl group of HAp, might be involved in the activation of alkanes. ${ }^{[14]}$ In such selective oxidation reactions, that are governed by the Mars and Van Krevelen mechanism, ${ }^{[15]}$ the challenge consists in 
the selective activation of the $\mathrm{C}-\mathrm{H}$ bond of propane, while avoiding overoxidation of both the alkane reactant and the alkene targeted product. If it is well accepted that highly-polymerized oxide-like catalytic species are detrimental to the control of the alkene selectivity, it is still controversial whether metal units with limited nuclearity or isolated species should be favored. ${ }^{[16]}$ Moreover, the activation of a $\mathrm{C}-\mathrm{H}$ bond of propane, which has been reported to be rate determining in the ODHP reaction, remains an open question. ${ }^{[13 b]}$ Both homolytic bond cleavage leading to a propyl radical ${ }^{[17]}$ and heterolytic splitting have been considered. ${ }^{[16 a, 18]}$ The latter proposal has been associated with the involvement of nucleophilic oxygen species such as $\mathrm{V}=\mathrm{O}$ entities $\left.{ }^{[13 a}, 16 a\right]$, and the beneficial influence of basicity promoted by alkali doping has been reported. ${ }^{[18 a, 19]}$, However, the nature of the oxygen species involved in the proton abstraction remained scarcely discussed. In contrast, acid-base properties are more often discussed to account for the propene selectivity, even though some inconsistencies still remain: Brønsted acidity was considered to be beneficial toward the desorption ability of propene ${ }^{[19 b, 20]}$, which may appear controversial as a proton is an electron-deficient species and propene is an electron-rich molecule. Accordingly, Grzybowska and coll. rather reported that low acidity and high basicity favor the desorption of the olefin ${ }^{[19 c, 21]}$.

In this context and given the tunable acid-base properties of HAps associated with the control of their stoichiometry (usually expressed as the Ca / P molar ratio descriptor), ${ }^{[22]}$ the vanadium-modified hydroxyapatites appear as a model system to investigate the role of the basicity in the activation of propane. In addition, contrary to the deposition of vanadium over HAp surfaces using an impregnation method, which prevents a careful control of the vanadium environment, ${ }^{[12 e,}$ 12f, $\left.12 \mathrm{~h}, 23\right]$ the functionalization of HAps by substituting the phosphate groups for the vanadate ones provides a unique opportunity to investigate model bi-functional catalysts associating isolated vanadium species and tunable acid-base properties.

However, the incorporation of vanadium in HAps as framework isolated species is not straightforward. Such an incorporation was reported to be either limited to low vanadium content, ${ }^{[2 f]}$ or associated with 
highly defective hydroxyapatite materials as shown by the high $\mathrm{Ca} /(\mathrm{P}+\mathrm{V})$ molar ratio (overstoichiometric HAps) ${ }^{[24]}$ that is associated with carbonation of the related samples. ${ }^{[25]}$ It was also suggested that the full substitution of phosphates by vanadate groups in the apatite structure might result in the preferential stabilization of vanadate oxyapatite $\left(\mathrm{Ca}_{10}\left(\mathrm{VO}_{4}\right)_{6} \mathrm{O}\right) \cdot{ }^{\left[{ }^{[2 f]}\right.}$ Recently, we succeeded in synthesizing $\mathrm{Ca}_{10}\left(\mathrm{PO}_{4}\right)_{6-x}\left(\mathrm{VO}_{4}\right)_{x}(\mathrm{OH})_{2}$ solid solutions $(0 \leq x \leq 6)$ (Figure $\mathrm{S1}$ ), while maintaining the targeted stoichiometric $\mathrm{Ca} /(\mathrm{P}+\mathrm{V})$ molar ratio to a value of 1.67 over the whole composition range (except for the fully substituted sample with $x=6$ ). ${ }^{[26]}$ This was achieved thanks to a one pot coprecipitation synthesis carried out with continuous adjustment of the $\mathrm{pH}$ of the precipitation medium to 9 during the whole precipitation step at $353 \mathrm{~K} \cdot{ }^{[26]}$ Yet the catalytic properties of such highly-loaded vanadium-modified HAps have not been investigated to our knowledge.

The aim of this study was to investigate the catalytic properties of the $\mathrm{Ca}_{10}\left(\mathrm{PO}_{4}\right)_{6-x}\left(\mathrm{VO}_{4}\right)_{x}(\mathrm{OH})_{2}$ solid solutions for the transformation of propane to propene in the presence of oxygen (oxidative dehydrogenation of propane (ODHP) conditions) and to discuss the possible role of basicity in the activation of propane. The influence of the incorporation of increasing vanadium contents into the bulk of HAps on the surface composition of the as-prepared catalysts will be discussed on the basis of XPS and CO-FTIR data. In the absence of nucleophilic vanadyl bonds in this system, ${ }^{[26]}$ the involvement of other peculiar oxygen species ${ }^{[19 a]}$ in the activation of propane will be investigated. Given the possible influence of vanadium on the stabilization of oxyapatite, ${ }^{\left[{ }^{[2]}\right.}$ and the high temperatures applied in the reaction, the structural organization of the $\mathrm{OH}$ groups stacked along the channels was investigated both in the as-prepared samples and in the thermally-activated ones. XRD being inappropriate to discriminate between the isostructural hydroxy- and oxy-apatite materials, the quantification of the $\mathrm{OH}$ groups present in the as-prepared materials was achieved by ${ }^{1} \mathrm{H}$ NMR. In situ DRIFT and in situ measurements of the ionic properties of the V-modified HAps were complementary performed to follow the thermally-activated dynamic processes occurring in the $\mathrm{OH}$ channels. ${ }^{[7 c, 27]}$ The basicity of the species generated at high temperature was probed by the 2-methyl-3-butyn-2-ol (MBOH) model reaction. ${ }^{[28]}$ The role of the basicity on the surface reactivity of the V-modified HAp samples under 
reductive ( $\left.\mathrm{H}_{2}-\mathrm{TPR}\right)$ and oxidative (ODHP) conditions will be discussed. Finally, the synergistic effects between the bulk ionic conduction properties, measured under ODHP operando conditions, and the catalytic activity will help revisiting some conceptual key points usually associated to the involvement of the Mars and Van Krevelen mechanism, putting particular emphasis on the role of strong basic species generated in situ on the activation process of propane.

\section{Results and Discussion}

\section{Bulk chemical composition versus surface chemical composition}

\subsection{Bulk chemical composition}

The bulk chemical compositions (ICP) of the $\mathrm{Ca}_{10}\left(\mathrm{PO}_{4}\right)_{6-x}\left(\mathrm{VO}_{4}\right)_{x}(\mathrm{OH})_{2}$ materials are in very good accordance with the nominal ones (Table 1). The bulk V/P molar ratios are also very close to the expected values confirming the stoichiometric incorporation of vanadium in the apatite framework. In addition, the bulk $\mathrm{Ca} /(\mathrm{P}+\mathrm{V})$ molar ratios were found to be close to 1.67 indicating that stoichiometric hydroxyapatites have been successfully prepared for the samples with $x<6$. The higher $\mathrm{Ca} /(\mathrm{P}+\mathrm{V})$ molar ratio obtained for the fully V-substituted sample $(x=6)$ is attributed to carbonate incorporation that is favored during the precipitation step under high $\mathrm{pH}$ conditions. ${ }^{[26]}$

Table 1. Specific surface areas, bulk and surface chemical compositions for $\mathrm{Ca}_{10-x}\left(\mathrm{PO}_{4}\right)_{6-x}\left(\mathrm{VO}_{4}\right)_{x}(\mathrm{OH})_{2}$ samples determined by ICP and XPS, respectively

\begin{tabular}{llllllc}
\hline $\begin{array}{l}\text { Nominal } \\
\text { vanadium } \\
\text { content } x\end{array}$ & nominal & ICP & XPS & ICP & XPS & $\begin{array}{l}\text { Specific } \\
\text { surface } \\
\text { area }\left(\mathrm{m}^{2} \mathrm{~g}^{-1}\right)\end{array}$ \\
\hline 0 & - & - & - & 1.67 & 1.30 & 35 \\
0.78 & 0.15 & 0.12 & 0.04 & 1.67 & 1.49 & 44 \\
3.00 & 1.00 & 0.94 & 0.82 & 1.66 & 1.82 & 40 \\
4.00 & 2.00 & 1.95 & 1.66 & 1.67 & 2.06 & 38 \\
5.22 & 6.69 & 6.24 & 4.28 & 1.66 & 2.27 & 20 \\
6.00 & - & - & - & 1.76 & 2.53 & 20 \\
\hline
\end{tabular}




\subsection{Surface layer composition}

$\mathrm{X}$-Ray photoelectron spectroscopy (XPS) measurements show the presence of $\mathrm{V}^{5+}$ species, with binding energy values of the $V_{2 p}$ core level ranging from 516.8 to $517.0 \mathrm{eV}$ for all of the samples. The area of the peaks corresponding to the $2 p$ core levels of $C a, V$ and $P$ were used to estimate the surface $C a /(P+V)$ and V/P molar ratios (Table 1). Ospina et al. suggested that crystalline hydroxyapatites exhibit either phosphates or calcium-rich terminations ${ }^{[29]}$. In accordance with what was reported earlier in the absence of vanadium in the hydroxyapatite structure, ${ }^{[30]}$ the surface $\mathrm{Ca} /(\mathrm{P}+\mathrm{V})$ molar ratio (XPS) was found to be lower than the bulk one (ICP) for the V-free sample $(x=0$, Table 1$)$. For V-substituted samples, the surface $\mathrm{Ca} /(\mathrm{P}+\mathrm{V})$ molar ratio was found to increase as the $\mathrm{V}$ content increased showing that the incorporation of $\mathrm{V}$ in the apatite structure promoted $\mathrm{Ca}$ enrichment in surface terminations. Despite this $\mathrm{Ca}$ enrichment trend, the surface terminations of $\mathrm{Ca}_{10}\left(\mathrm{PO}_{4}\right)_{5.22}\left(\mathrm{VO}_{4}\right)_{0.78}(\mathrm{OH})_{2}$ remained Ca deficient. The surface terminations of the samples exhibiting $x$ values higher than or equal to 3 were found to be Ca-enriched. In the whole composition range, the surface V/P molar ratios are found to be significantly lower than the bulk ones (Table 1).

\subsection{Top surface composition}

In order to obtain a more precise description of the composition of the top surface, the surfaces of four samples $(x=0,3,5.22$ and 6$)$ were complementary probed by FTIR following their interaction with $\mathrm{CO}$ at $100 \mathrm{~K}$. Various types of surface acidic sites are likely to interact with CO: (i) terminated Brønsted acid sites such as PO-H and/or VO-H species, (ii) $\mathrm{Ca}^{2+}$ Lewis acid sites and (iii) isolated $\mathrm{V}^{\mathrm{n}+}$ Lewis acid sites. Table 2 lists the $v C O$ infrared contributions reported earlier on various materials. Given the proximity of these contributions, the influence of the CO coverage and the competitive adsorption processes that are driven by the relative acidic strengths and the site accessibilities, as already reported elsewhere, ${ }^{[30 a]}$ the assignment of the $\mathrm{CO}$ contributions observed for the surface acid sites can be identified by combining the complementary data obtained upon both the adsorption and the desorption steps. 
Table 2. : Infrared contributions reported for low-temperature interaction of $\mathrm{CO}$ with $\mathrm{PO}-\mathrm{H}, \mathrm{Ca}^{2+}$ and $\mathrm{V}^{\mathrm{nt}}$ surface species reported in earlier studies.

\begin{tabular}{llll}
\hline $\begin{array}{l}\text { acid } \\
\text { site }\end{array}$ & $v \mathrm{CO}\left(\mathbf{c m}^{-1}\right)$ & Samples & Refs \\
\hline $\mathrm{PO}-\mathrm{H}$ & $2178-2170^{*}$ & Hydroxyapatite & {$[2 \mathrm{~d}, 30 \mathrm{a}, 31]$} \\
$\mathrm{VO}-\mathrm{H}$ & $2168^{*}$ & $\mathrm{~V}^{-} \mathrm{Al}_{2} \mathrm{O}_{3}-\mathrm{TiO}_{2}$ & {$[32]$} \\
& $2182-2197^{\$}$ & Ca-exchanged zeolite & {$[2 \mathrm{~d}, 31 \mathrm{~b}, 33]$} \\
$\mathrm{Ca}^{2+}$ & $\sim 2184$ & P-rich termination of hydroxyapatite & {$[2 \mathrm{~d}, 30 \mathrm{a}]$} \\
& 2182 and 2185 & Ca-rich termination of hydroxyapatite & {$[2 \mathrm{~d}, 30 \mathrm{a}, 31 \mathrm{~b}]$} \\
$\mathrm{V}^{\mathrm{n}+\mathrm{f}}$ & 2196 & $\mathrm{~V}^{4+}$-exchanged zeolite & {$[34]$} \\
\hline
\end{tabular}

*simultaneous perturbation of the corresponding $\mathrm{vOH}$ contribution, \$shift of the absorption band to higher wavenumbers with the transformation of multi- to mono-carbonyl species. ${ }^{[33 b]}$, ${ }^{\text {no }}$ data reported yet for $\mathrm{V}^{5+}$

Firstly, a slightly different behavior is observed during the CO adsorption step depending on the presence of phosphate groups $(x=0,3,5.2)$ or not $(x=6)$ in the samples (Figure 1). The first dose of CO $\left(0.0910^{-6} \mathrm{~mol}\right)$ leads to the appearance of an absorption band with a maximum at $2183 \mathrm{~cm}^{-1}$ for the sample with $x=6$, whereas contributions are observed at lower wavenumbers, 2178, 2174 and $2173 \mathrm{~cm}^{-1}$ for the samples with $x=0,3$ and 5.2, respectively. Further introduction of CO doses shifts progressively the maxima of the multicomponent band to lower wavenumbers (from 2178 to $2170 \mathrm{~cm}^{-}$ $\left.{ }^{1}\right)$ depending on the samples, due to both the titration of sites of lower acidity and to the formation of multicarbonyl species. With an equilibrium pressure of $133 \mathrm{~Pa}$ of $\mathrm{CO}$, an additional absorption contribution is observed at lower wavenumbers, $\sim 2145-2140 \mathrm{~cm}^{-1}$, that is ascribed to physisorbed CO. ${ }^{[35]}$ As already reported for $V$-free hydroxyapatite samples involving phosphate rich terminations, ${ }^{[31 a, 36]}$ the $\mathrm{VPO}-\mathrm{H}$ surface contributions were found to be simultaneously perturbed for the partially-substituted vanadium samples (Figure $\mathbf{S 2} \mathbf{a}, \mathbf{c}$ ). 

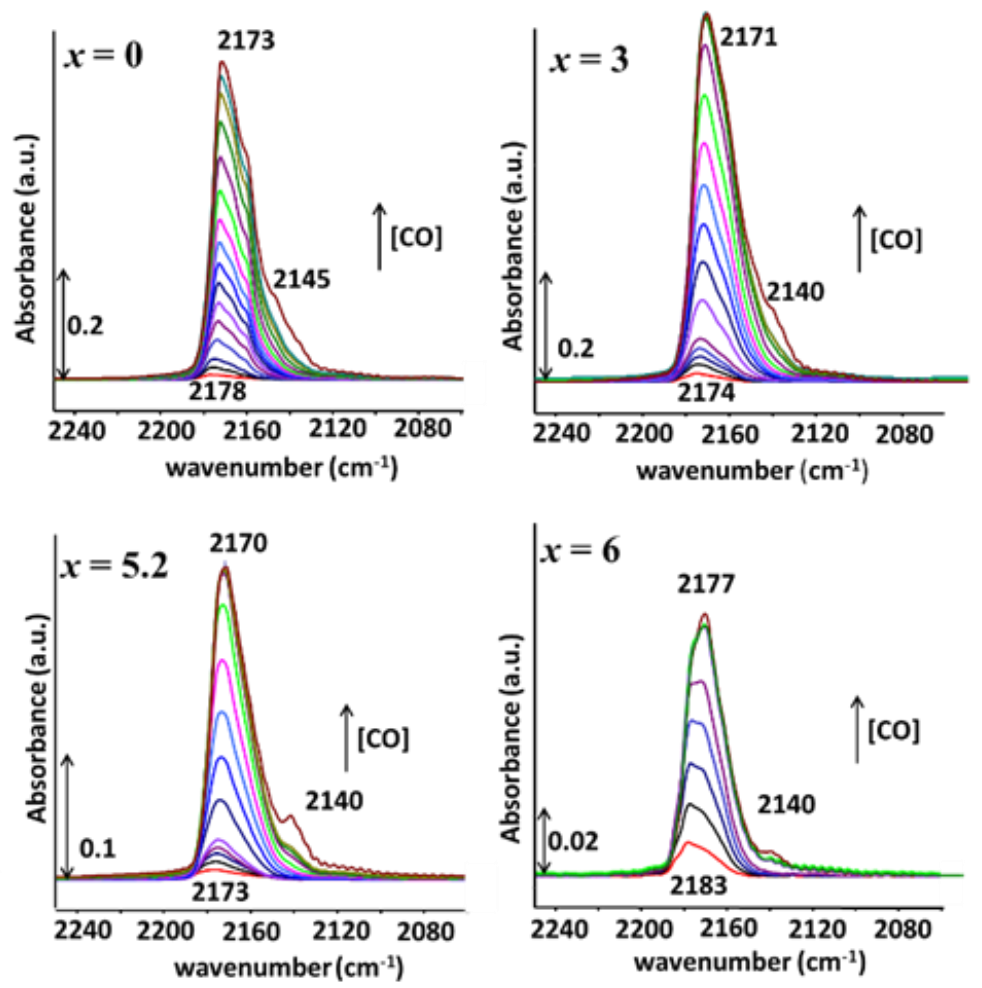

Figure 1. FTIR difference spectra in the $2230-2070 \mathrm{~cm}^{-1}$ region of self-supported wafers of $\mathrm{Ca}_{10}\left(\mathrm{PO}_{4}\right)_{6}$ ${ }_{x}\left(\mathrm{VO}_{4}\right)_{x}(\mathrm{OH})_{2}$ samples with $x=0,3,5.2$ and 6 after adsorption of incremental doses of $\mathrm{CO}$ up to an equilibrium pressure of $133 \mathrm{~Pa}$ at $100 \mathrm{~K}$
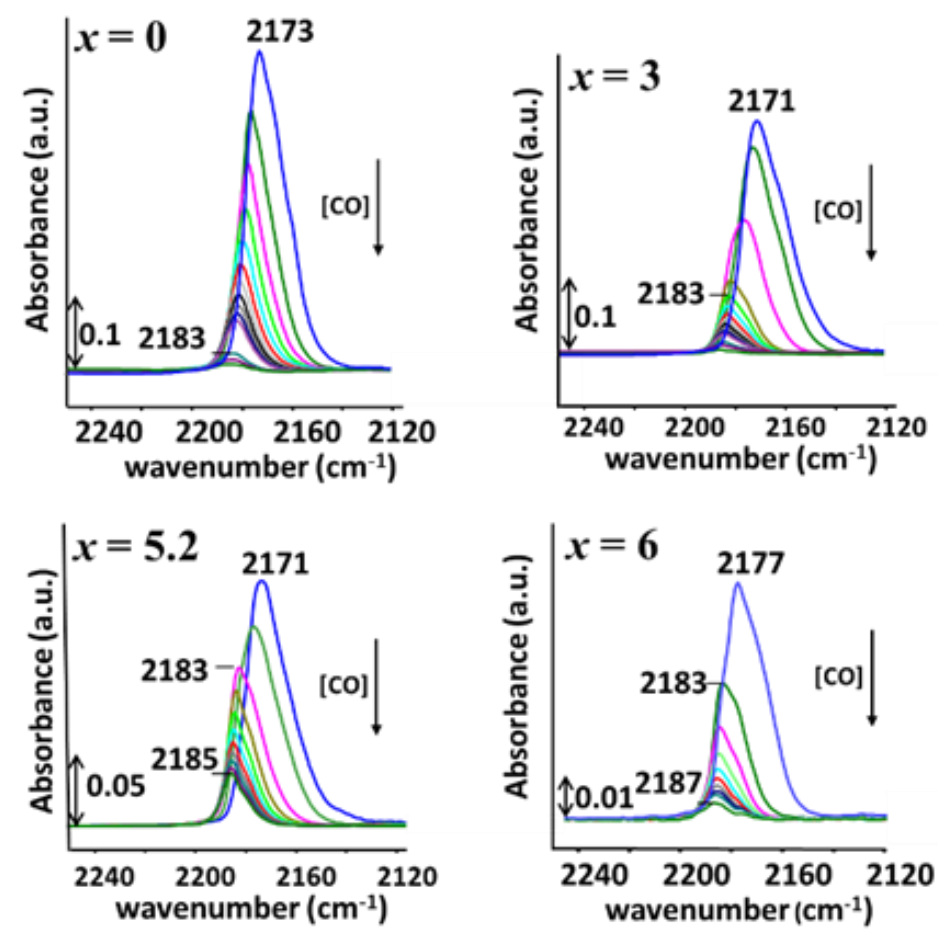

Figure 2. FTIR difference spectra in the $2230-2070 \mathrm{~cm}^{-1}$ region of self-supported wafers of $\mathrm{Ca}_{10}\left(\mathrm{PO}_{4}\right)_{6}$ ${ }_{x}\left(\mathrm{VO}_{4}\right)_{x}(\mathrm{OH})_{2}$ samples with $x=0,3,5.2$ and 6 upon progressive evacuation of $\mathrm{CO}$ under dynamic secondary vacuum. 
Given that very similar $v$ CO contributions $\left(2173-2178 \mathrm{~cm}^{-1}\right)$ were observed from the first CO dose introduced on the samples with $x=0,3$ and 5.22, it is thus concluded that, despite progressive surface enrichment in $\mathrm{Ca}^{2+}$ (Table 1), PO-H vibrators are still accessible to the $\mathrm{CO}$ probe molecule for all of the phosphate-containing samples. Weak $\mathrm{v} \mathrm{VO}-\mathrm{H}$ contributions were additionally detected in the $\mathrm{V}$-rich samples (Figure S2b) but, the absence of perturbation upon CO adsorption (Figure S2d), rather indicates a bulk location. In the case of $\mathrm{Ca}_{10}\left(\mathrm{PO}_{4}\right)_{0}\left(\mathrm{VO}_{4}\right)_{6}(\mathrm{OH})_{2}$, a $v \mathrm{CO}$ contribution is observed at 2183 $\mathrm{cm}^{-1}$ from the introduction of the first dose of $\mathrm{CO}$ (Figure 1). This contribution is unambiguously attributed to the interaction of $\mathrm{CO}$ with $\mathrm{Ca}^{2+}$ species. ${ }^{23,28,30}$ The observation of $\mathrm{Ca}^{2+}$ sites on the adsorption of $\mathrm{CO}$ for this sample is in line with the highest Ca-enriched surface termination of this sample, as indicated by the Ca/V XPS ratio (Table 1) together with the absence of PO-H vibrator.

Figure 2 shows the evolution of the CO contributions upon the evacuation step. CO is progressively released from the weakest acidic sites, whereas the remaining absorption band shifts to higher wavenumbers. Characteristic fingerprint of $\mathrm{Ca}^{2+}$ is now seen at $2183 \pm 1 \mathrm{~cm}^{-1}$ for all of the samples. This absorption band is observed more rapidly and with a higher intensity as the $x$ value increases. The residual band finally shifts to 2185 and $2187 \mathrm{~cm}^{-1}$ for $x=5.22$ and $x=6$, respectively. As supported by the peculiar calcium enrichment observed for these two samples (Table 1), this shift may be attributed to the existence of $\mathrm{Ca}^{2+}$ ions with different environments, which is in line with the presence of two independent Ca crystallographic sites in the apatite structure. ${ }^{[1]}$

\subsection{Surface relaxation processes}

Despite solid solutions are obtained with the expected nominal compositions, ${ }^{[26]}$ XPS analyses showed the surfaces to be vanadium deficient (Table 1). This was found to be consistent with the CO adsorption-desorption data underlying the lack of vanadium acidity in $\mathrm{PO}_{4}{ }^{3-}$-containing samples (section.1.3). This indicates that the vanadate tetrahedra are more deeply relaxed inside the surface layer compared to phosphate ones as illustrated in Figure 3a. 

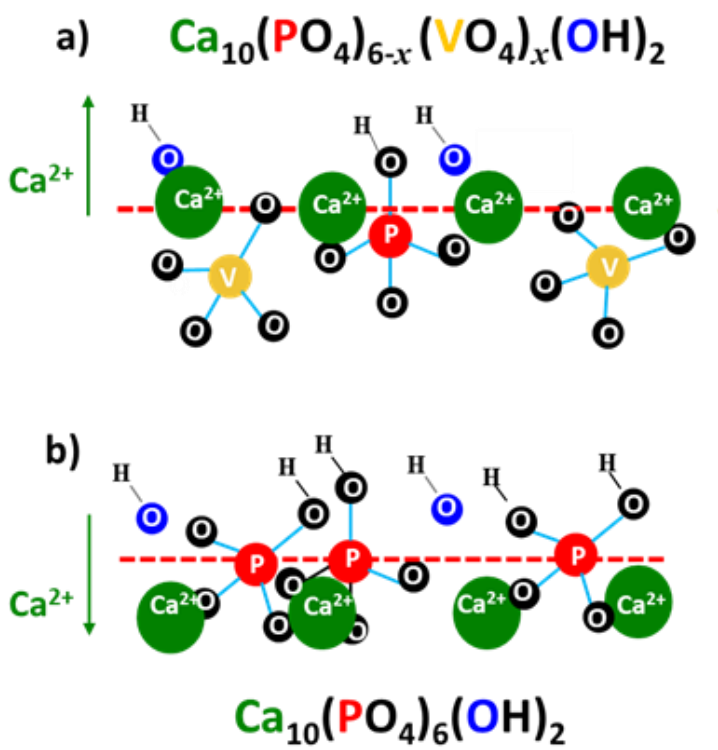

Figure 3. Schematic representation of the surface layer of a) $\mathrm{Ca}_{10}\left(\mathrm{PO}_{4}\right)_{6-x}\left(\mathrm{VO}_{4}\right)_{x}(\mathrm{OH})_{2}$ samples for $x \geq 3$ deduced from XPS and CO-FTIR studies revealing both the relative enrichment of the surface in calcium cations as the $x$ value increases and the deeper relaxation of vanadate groups compared to phosphate ones in the sub surface layer and b) typical $\mathrm{Ca}_{10}\left(\mathrm{PO}_{4}\right)_{6}(\mathrm{OH})_{2}$ enriched in protonated terminal phosphate groups. The red dash line indicates the top surface for the $\mathrm{Ca}_{10}\left(\mathrm{PO}_{4}\right)_{6-x}\left(\mathrm{VO}_{4}\right)_{x}(\mathrm{OH})_{2}$ samples.

In the case of $\mathrm{Ca}_{10}\left(\mathrm{PO}_{4}\right)_{6}(\mathrm{OH})_{2}$, the surface charge balance is usually achieved by protonation of the terminal phosphate groups, resulting in phosphate-enriched surfaces ${ }^{[37]}$ (Figure $\mathbf{3 b}$ ). In the case of the V-substituted HAp samples, as the phosphate content progressively decreases with increasing vanadium content incorporated in the bulk, the concentration in surface $\mathrm{PO}-\mathrm{H}$ groups decreases. This may explain why, to achieve the surface balance, a completely different surface relaxation process occurs as vanadium is increasingly present in the bulk (Figure 3), which eventually leads to an overexposure of surface calcium cations. Such a surface termination is supported by both the XPS data (Table 1, surface $\mathrm{Ca} / \mathrm{P}+\mathrm{V}$ molar ratios higher than those found in the bulk for $x \geq 3$ ) and the CO-FTIR data (increase in the relative intensity of the remaining $2183 \mathrm{~cm}^{-1}$ contribution upon the $\mathrm{CO}$ desorption step in Figure 2 and $2183 \mathrm{~cm}^{-1}$ contribution observed from the CO adsorption step for $x=6$ ). 


\section{$2 \mathrm{OH}$ versus $\mathrm{O}^{2-}$}

\subsection{As-synthesized samples}

DP ${ }^{1} \mathrm{H}$ NMR spectra of the as-synthesized materials show two main ${ }^{1} \mathrm{H}$ contributions (Figure 4). Apart from the signal around $5 \mathrm{ppm}$ that is assigned to physisorbed water, an intense peak typical of the structural $\mathrm{OH}$ groups ${ }^{[38]}$ is observed at about $0 \mathrm{ppm}$ for all of the materials. The presence of the latter signal discards the exclusive formation of $\mathrm{Ca}_{10}\left(\mathrm{VO}_{4}\right)_{6} \mathrm{O}$ vanadium oxyapatite. This signal is particularly narrow for the HAp samples with $x=0$ and 6 , which is in line their high crystallinity, as attested by XRD in an earlier report. ${ }^{[26]}$ The slight shift of this peak from -0.2 to 0 ppm for the HAp samples with $x=0$ and 6, respectively, is related to differences in local environments of the $\mathrm{OH}$ groups induced by the full replacement of the phosphate tetrahedra by the vanadate ones in the apatite framework. For other vanadium-rich samples ( $x=4$ and 5.22), the chemical shift of this peak is similar to that found for the sample with $x=6$, but these peaks appear to be broadened (FWMH values of 347 and $342 \mathrm{~Hz}$ for samples with $x=4$ and 5.22, respectively, compared to 283 and $289 \mathrm{~Hz}$ for samples with $x=6$ and 0 ). This peak broadening is ascribed to the simultaneous presence of two types of environments for the $\mathrm{OH}$ groups that leads to a decrease in crystallinity. The quantification of the $\mathrm{OH}$ groups present in the channels can be estimated by considering the areas of the peaks corrected for the change in molar weight of the samples as the value of $x$ increases. Compared to the $\mathrm{V}$-free HAp reference sample, $\mathrm{V}$ rich samples show significantly lower contents of $\mathrm{OH}$ groups. Given that we unambiguously concluded from XRD to the formation of a V-HAp solid solutions rather than mixtures of $\mathrm{Ca}_{10}\left(\mathrm{PO}_{4}\right)_{6}\left(\mathrm{VO}_{4}\right)_{0}(\mathrm{OH})_{2}$ and $\mathrm{Ca}_{10}\left(\mathrm{PO}_{4}\right)_{0}\left(\mathrm{VO}_{4}\right)_{6}(\mathrm{OH})_{2}$, these data indicate that the vanadium apatite solid solutions are partly dehydroxylated in oxy-hydroxy-apatite $\mathrm{Ca}_{10}\left(\mathrm{PO}_{4}\right)_{6-x}\left(\mathrm{VO}_{4}\right)_{x}(\mathrm{OH})_{2-2 y} \mathrm{O}_{y}$ structures, at least for $\mathrm{V}$-rich samples. Among the samples investigated, that with a $x$ value of 5.22 exhibits the lowest $\mathrm{OH}$ content,

$33 \%$ less than in V-free HAp to which corresponds a $y$ value of about 0.34 $\left(\mathrm{Ca}_{10}\left(\mathrm{PO}_{4}\right)_{0.78}\left(\mathrm{VO}_{4}\right)_{5.22}(\mathrm{OH})_{1.32} \mathrm{O}_{0.34}\right)$. 


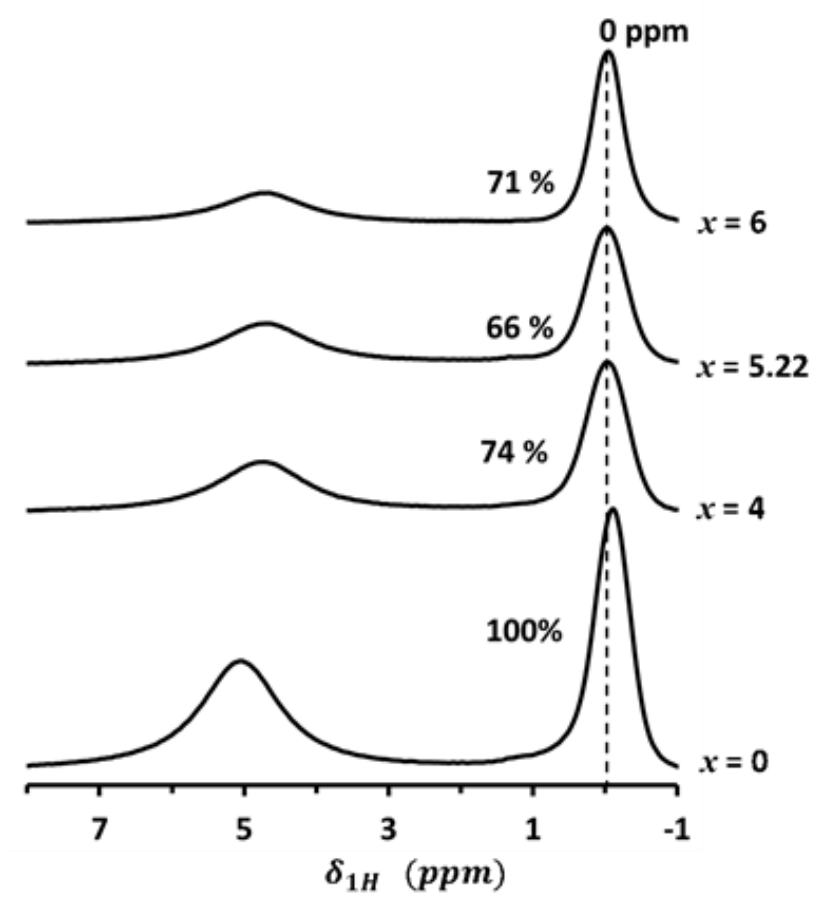

Figure 4. ${ }^{1} \mathrm{H}$ DP NMR spectra of $\mathrm{Ca}_{10}\left(\mathrm{PO}_{4}\right)_{6-x}\left(\mathrm{VO}_{4}\right)_{x}(\mathrm{OH})_{2-2 y} \mathrm{O}_{y}$ samples $(x=0,4,5.22$ and 6$)$ and $\%$ of channel $\mathrm{OH}$ groups measured compared to that expected for the V-HAp structure (reference $100 \%$ (y $=0$ ) for the V-free HAp sample whose generic formulae is $\left.\mathrm{Ca}_{10}\left(\mathrm{PO}_{4}\right)_{6}(\mathrm{OH})_{2}\right)$.

\subsection{Influence of thermal activation}

\section{2.a DRIFTS}

Figure 5 shows that the as-synthesized samples (bottom spectra recorded at $303 \mathrm{~K}$ ) exhibit the typical $\mathrm{vOH}$ band associated with the $\mathrm{OH}$ groups stacked along the channels. ${ }^{[1,25,31 a]}$ The position of the maximum of the band is found to be red-shifted from 3570 to $3550 \mathrm{~cm}^{-1}$ on vanadium incorporation .${ }^{[24,39]}$ Such a lengthening of the $\mathrm{O}-\mathrm{H}$ bond is in line with an enlargement of the tunnels associated with an increase in the cell volume. ${ }^{[26]}$ After disappearance of the broad contribution around $3500-3250$ $\mathrm{cm}^{-1}$ that is ascribed to adsorbed water, the increase in temperature leads to the progressive and reversible red-shift of $\sim 4 \mathrm{~cm}^{-1}$ of the $\mathrm{OH}$ contributions at $3570-3550 \mathrm{~cm}^{-1} \cdot{ }^{[25]} \mathrm{A}$ shoulder contribution also appears around $3530 \mathrm{~cm}^{-1}$ for $\mathrm{Ca}_{10}\left(\mathrm{PO}_{4}\right)_{6}\left(\mathrm{VO}_{4}\right)_{0}(\mathrm{OH})_{2}$ and $\mathrm{Ca}_{10}\left(\mathrm{PO}_{4}\right)_{5.22}\left(\mathrm{VO}_{4}\right)_{0.78}(\mathrm{OH})_{2-y} \mathrm{O}_{\mathrm{y}}$ and at 3520 $\mathrm{cm}^{-1}$ for $\mathrm{V}$-rich samples $(x=5.22$ and 6$)$. The onset formation temperature of this shoulder contribution 
decreases as the vanadium content increases, i.e. $623 \mathrm{~K}$ for $x=0$ and 0.78 , and 463 and $383 \mathrm{~K}$ for $x=$ 5.22 and 6, respectively. The relative intensity of this shoulder contribution increases as the temperature increases up to $773 \mathrm{~K}$. After $90 \mathrm{~min}$ at $773 \mathrm{~K}$, no change was observed in the spectra recorded at this particular temperature (comparison of the spectra in dash and solid lines at $773 \mathrm{~K}$ in Figure 5).

The spectra recorded during the cooling of the samples (dash lines) show a more pronounced decrease of the intensity of the $3520-3530 \mathrm{~cm}^{-1}$ shoulder contribution for the V-containing samples compared to the V-free sample. This shoulder contribution is indeed still observable at RT for the V-free sample, whereas this is no longer the case for the V-containing samples. Hence the presence of vanadium definitely influences both the appearance and the disappearance of this shoulder contribution with temperature, which assignment is discussed below. 

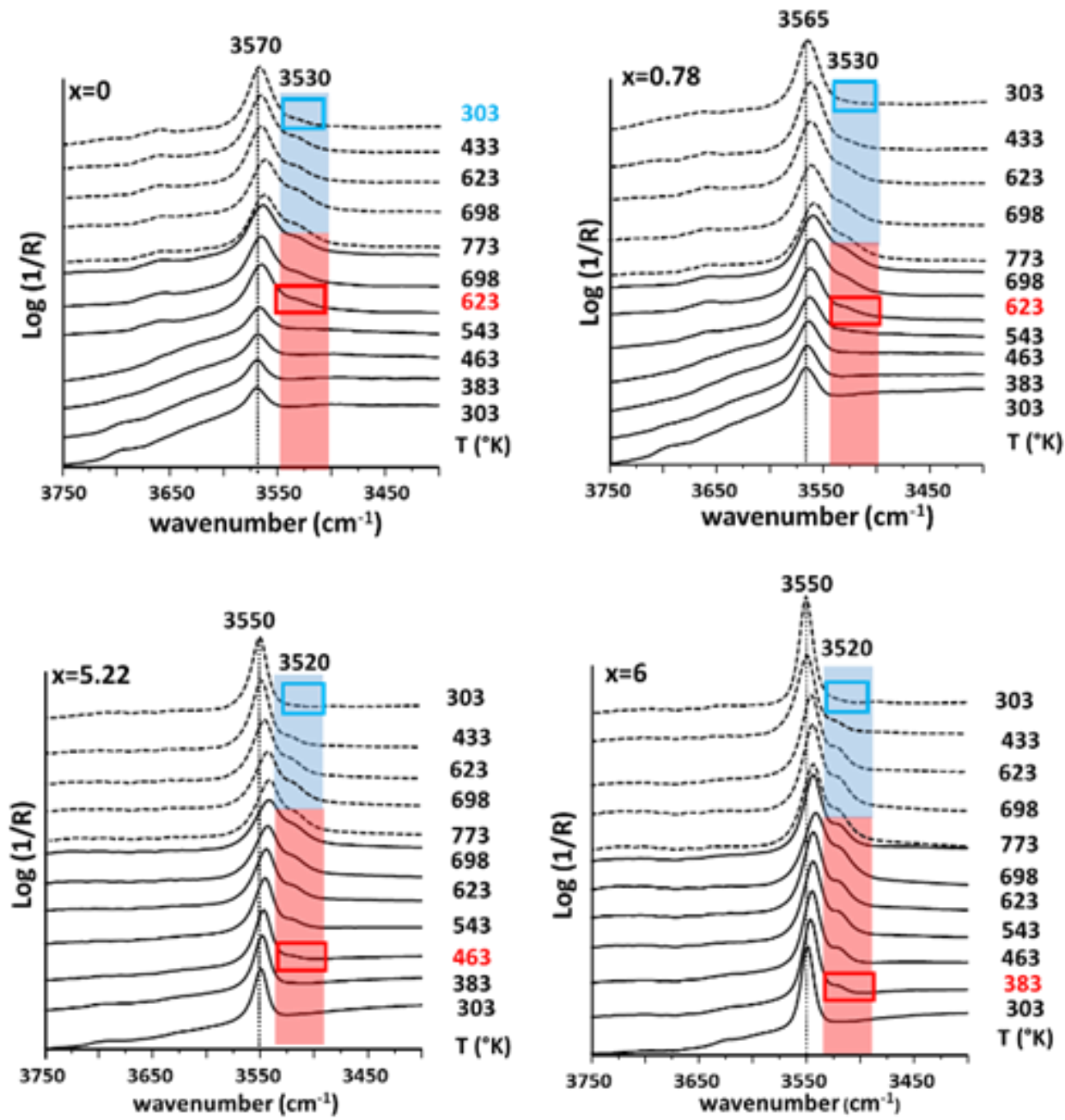

Figure 5. DRIFT spectra of the $\mathrm{Ca}_{10}\left(\mathrm{PO}_{4}\right)_{6-x}\left(\mathrm{VO}_{4}\right)_{x}(\mathrm{OH})_{2-2 y} \mathrm{O}_{y}$ samples $(x=0,0.78,5.22$ and 6$)$ recorded upon increasing temperature $(5 \mathrm{~K} / \mathrm{min})$ up to $773 \mathrm{~K}$ under inert flow (solid lines) showing the appearance of a shoulder contribution at $3530-3520 \mathrm{~cm}^{-1}$ and, after maintaining the temperature at $773 \mathrm{~K}$ for $90 \mathrm{~min}$, upon cooling (dash lines) with the progressive decrease of the shoulder contribution and its full vanishing for the sample with $\mathrm{x}=0$. The temperature written in red indicates the onset temperature for the detection of the shoulder contribution during the temperature rise, as also pointed out by the red rectangles. Blue rectangles enable to appreciate the reversibility of the process during the cooling down step.

\section{2.b lonic conductivity}

The ionic conductivity of hydroxyapatites was estimated by impedance spectroscopy under various conditions of temperature and atmosphere. ${ }^{[7 d, 40]}$ The dependence of ionic conductivity on temperature under $\mathrm{Ar}$ flow is displayed in Figure 6 for $\mathrm{Ca}_{10}\left(\mathrm{PO}_{4}\right)_{0.78}\left(\mathrm{VO}_{4}\right)_{5.22}(\mathrm{OH})_{1.32} \mathrm{O}_{0.34}$. The ionic conductivity is found to be stable between 298 and $673 \mathrm{~K}$, and to slightly increase up to $873 \mathrm{~K}$ and then 
more markedly for higher temperatures. The lower $\mathrm{H}^{+}$ion-conductivity found in the present work compared to those reported in earlier studies ${ }^{[7 \mathrm{~d}, 40]}$ may be attributed to the lower density of the pellet used in the present study. The activation energies of the ionic conductivity process were calculated for $\mathrm{Ca}_{10}\left(\mathrm{PO}_{4}\right)_{0.78}\left(\mathrm{VO}_{4}\right)_{5.22}(\mathrm{OH})_{1.32} \mathrm{O}_{0.34}$ within the previously defined ranges of temperatures (Figure 6) according to the slopes of the Arrhenius plots shown in Figure S3. The activation energy in the lowtemperature range $(298-673 \mathrm{~K})$ is $\sim 0.03 \mathrm{eV}$, indicating a low mobility of protons. This value is characteristic of the energy needed for the polarization $\mathrm{OH}^{-}$ions in the apatite structure along the $c$ axis. ${ }^{[7 \mathrm{~d}]}$ The activation energy in the medium-temperature range $(673-873 \mathrm{~K}), \sim 0.3 \mathrm{eV}$ is characteristic of the diffusion of protons in the apatite structure according to a Grotthus mechanism. ${ }^{[41]}$ In this mechanism, the protons move along the $c$-axis in the apatite structure because of the formation / scission of $\mathrm{O}-\mathrm{H}$ bonds. At high temperature range $(>873 \mathrm{~K})$, the activation energy ( $1.64 \mathrm{eV})$ rather corresponds to the mobility of $\mathrm{OH}^{-}$or $\mathrm{O}^{2-}$ anions according to earlier reports. ${ }^{[27 b, 42]}$ It was found that the activation energy increases as the content of vanadium in the samples increases. This may be due to the enlargement of the channels in the apatite structure due to the substitution of phosphates by vanadates. ${ }^{[43]}$

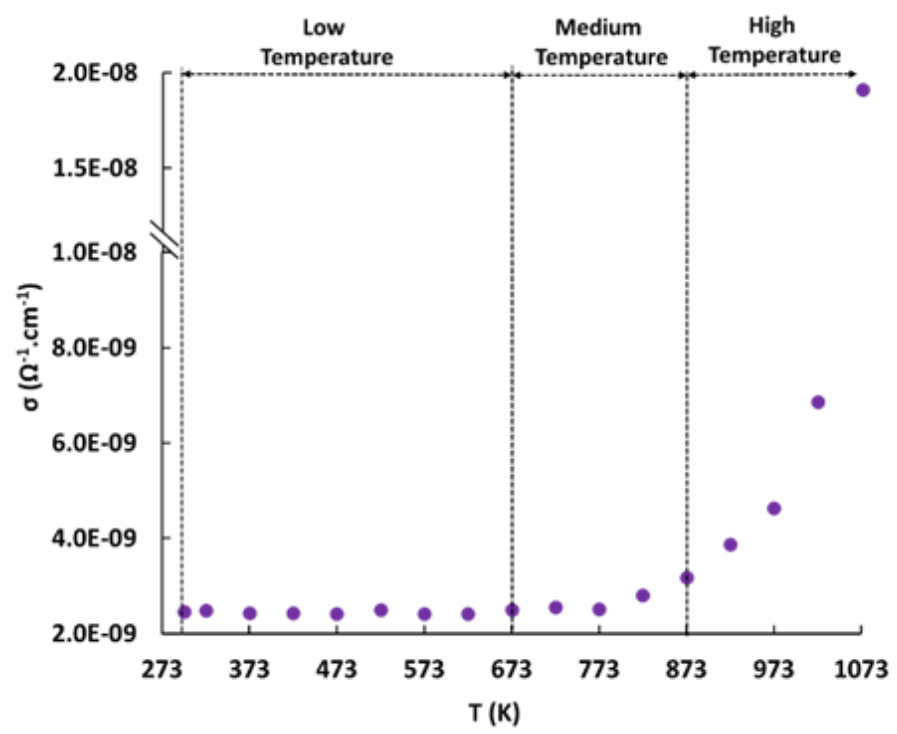

Figure 6. Dependence of total ionic conductivity as a function of temperature of $\mathrm{Ca}_{10}\left(\mathrm{PO}_{4}\right)_{0.78}\left(\mathrm{VO}_{4}\right)_{5.22}(\mathrm{OH})_{1.32} \mathrm{O}_{0.34}$ under Ar flow. 


\subsection{Thermally activated dynamic processes occurring inside the channels}

Besides an impact on the surface relaxation, the NMR study reveals that the incorporation of vanadium in the apatite framework tends to lower the concentration in $\mathrm{OH}$ groups present inside the channels running along the $c$-axis (Figure 4) (with the lowest concentration obtained in the case of $x=5.22$ ). This peculiarity is significant of the prevailing formation of $\mathrm{Ca}_{10}\left(\mathrm{PO}_{4}\right)_{6-x}\left(\mathrm{VO}_{4}\right)_{x}(\mathrm{OH})_{2-2 y} \mathrm{O}_{y}$ oxy-hydroxyapatite solid solution in the presence of vanadium. In addition, in situ DRIFT data show that thermallyactivated modifications inside the $\mathrm{OH}$ channels are also promoted by vanadium, which results in the appearance of a shoulder contribution around $3530 \mathrm{~cm}^{-1}$ (Figure 5). The origin of this shoulder contribution at $3530 \mathrm{~cm}^{-1}$ already reported earlier in the case of non-substituted hydroxyapatites is still being debated._Given the rather long distance between two adjacent $\mathrm{OH}$ groups $(0.344 \mathrm{~nm})$, the $\mathrm{OH}$ vibrators can be considered as isolated species, which is consistent with the narrowness of the $\mathrm{vOH}$ band. ${ }^{[\mathrm{dd}]}$ Although proposed by several authors, ${ }^{[31 b, 44]}$ the switching between up and down orientations of the protons occurring upon the phase transition from monoclinic to hexagonal symmetry ( $483 \mathrm{~K}$ ) ${ }^{[44-45]}$ cannot be taken as responsible for the shoulder appearance occurring at higher temperatures (623 K for $x=0$ ). The persistence of the shoulder contribution after return to RT for the sample with $x$ $=0$ (Figure 5) also discards the involvement of $\mathrm{H}$-bonding interaction associated with a proton migration occurring at high temperatures. Even though such a proton migration pathway might imply cooperation of either neighboring phosphate $\operatorname{groups}^{[27 c, 46]}$ or even cations, ${ }^{[7 b]}$ only a direct jump of proton between adjacent sites is reported in Figure $7 \mathbf{a}$ for the sake of clarity. This proton conduction dynamic process requires the existence of defects in the $\mathrm{OH}^{-}$channels of the oxy-hydroxy-apatite material, the so-called "proton vacant $\mathrm{OH}^{-}$sites", i.e. $\mathrm{O}^{2-}$ anions as schematically represented in Figure 7a. This conduction process is thus closely related to the dehydration process occurring along the channels that controls the concentration of $\mathrm{O}^{2-}$ ions and results in a shift of the equilibrium towards increasing concentration in $\mathrm{O}^{2-}$ leading to $\mathrm{Ca}_{10}\left(\mathrm{PO}_{4}\right)_{6-x}\left(\mathrm{VO}_{4}\right)_{x}(\mathrm{OH})_{2-2 y-2 z} \square_{z} \mathrm{O}_{y+z}$ oxy-hydroxy-apatite phase, where $\square$ stands for a new $\mathrm{OH}$ vacancy formed upon dehydration process). Hence, we propose that the 
appearance of the IR shoulder contribution is indirectly related to this process and is ascribed to $\mathrm{H}$ bonding interaction between the remaining $\mathrm{O}-\mathrm{H}$ groups and the adjacent $\mathrm{O}^{2-}$ species.

Such a $\mathrm{H}$-bonding phenomenon is supposed to be favored by the slight displacement of the $\mathrm{O}^{2-}$ species compared to the initial location of the native $\mathrm{OH}^{-}$groups, ${ }^{[7 a]}$ as illustrated in Figure 7a (3-7). The proposed assignment is also fully supported by the studies in which fluoride was incorporated in the channels, which eventually resulted in the appearance of a similar IR band. ${ }^{[4]]}$ As illustrated in Figure 7a, the diffusion of protons along the $c$-axis finally leads to the exposure $\mathrm{O}^{2-}$ ions pre-existing as defects or formed upon the dehydration process on the surface. The presence at high temperature of surface $\mathrm{O}^{2-}$ ions emerging from the $\mathrm{OH}$ channels of hydroxyapatite was recently demonstrated in an operando study of the ethanol to $n$-butanol catalytic reaction operating at $623 \mathrm{~K}$ after activation at $873 \mathrm{~K}$ through the perturbation of the $3530 \mathrm{~cm}^{-1}$ shoulder. ${ }^{[48]}$ Such $\mathrm{O}^{2-}$ species being surrounded by triangles of calcium cations (Figure $\mathbf{7 b}$ ) are expected to be strongly basic. These species are also expected to be very sensitive to traces of water, which explains the metastability of the oxy-apatite phase formed at high temperatures, as shown by the disappearance of the shoulder contribution after cooling down to RT in the V-modified HAps (Figure 5). Vanadium favors the dynamic $2 \mathrm{OH}^{-} \rightarrow \mathrm{O}^{2-}+\mathrm{H}_{2} \mathrm{O}$ transformation: (i) As deduced from ${ }^{1} \mathrm{H} N M R, \mathrm{O}^{2-}$ species are present in greater amounts at room temperature in V-rich samples compared to the $\mathrm{V}$-free sample (Figure 4), (ii) $\mathrm{O}^{2-}$ species are also formed at lower temperature as the vanadium content increases (Figure 5), and (iii) $\mathrm{O}^{2-}$ species are more easily reversibly transformed to $\mathrm{OH}^{-}$groups, as shown by the disappearance of the shoulder after cooling down to RT in the V-containing samples (Figure 5). 


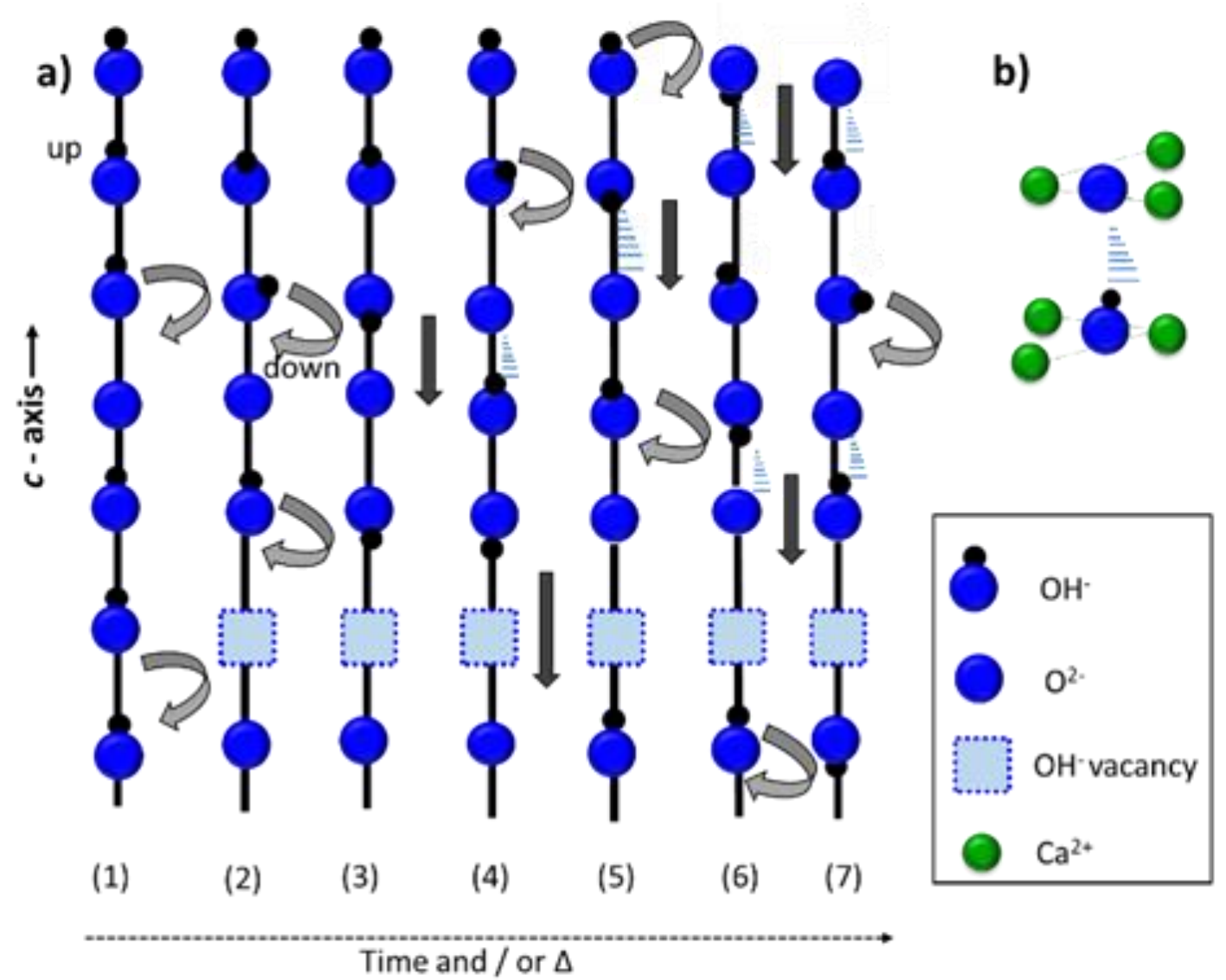

Figure 7. a) Schematic representation of the thermally-activated proton migration mechanism in the oxy-hydroxy-apatite system, adapted from Nakamura et al. ${ }^{[7 \mathrm{~d}]}$ and Horiuchi et al. ${ }^{[7 \mathrm{c}]}$ This schematic representation shows (1) the stacking of $\mathrm{OH}^{-}$along the $\mathrm{c}$ axis including $\mathrm{O}^{2-}$ native defects present in vanadium-modified apatites, and the proton rotation activated at low temperature that are favored by the polarization induced by the defective stacking, (2) $\mathrm{O}^{2-}$ species generated upon thermal dehydration together with a $\mathrm{OH}$ vacancy site (3-7) and the proton transportation along the $c$-axis activated in the medium range temperature. The proton migration occurs from the upper layers to the lower ones with time, resulting in $\mathrm{O}^{2-}$-climbing up from the bulk to the surface. Slight displacement of the $\mathrm{O}^{2-}$ ion from the initial position of the $\mathrm{OH}^{-}$group allows the formation of $\mathrm{O}^{2-} \ldots \mathrm{HO}^{-} \mathrm{H}$-bonding interaction. b) $\mathrm{Ca}^{2+}$ triangles coordination sphere of the $\mathrm{OH}^{-}$and $\mathrm{O}^{2-}$ anions present in the channels.

\section{Surface reactivity}

\subsection{Control of the acid-base properties by the HAp composition: $\mathrm{MBOH}$ model reaction}

The acid-base reactivity of the samples was probed by the $\mathrm{MBOH}$ model reaction. This molecule is converted along two parallel routes leading to the formation of different products depending on the 
involvement of acid and/or basic pathways: 3-methyl-butene-1-yne (Mbyne) and/or 3-methylbut-2enal (prenal) are formed on acidic sites, whereas acetone and acetylene are formed in equimolar amounts in the case of a basic route involving acid-base pairs. ${ }^{[28]}$ While the characterization of the acidity of $\mathrm{VMgO}^{[20 \mathrm{a}, 49]}$ and $\mathrm{VPO} / \mathrm{TiO}_{2}{ }^{[20 b]}$ catalysts also active for ODHP was reported, the $\mathrm{MBOH}$ reactivity was only investigated on $\mathrm{VO}_{2} \mathrm{P}_{2} \mathrm{O}_{7}$, which has been found to be active for the selective oxidation of $n$-butane to maleic anhydride. ${ }^{[50]} \mathrm{MBOH}$ was found to be mainly converted to Mbyne (90 \% selectivity) on $\mathrm{VO}_{2} \mathrm{P}_{2} \mathrm{O}_{7}{ }^{[51]}$, which illustrates the acidic character of this catalyst. Despites the bulk incorporation of vanadium along the series of samples, no formation of Mbyne nor prenal is observed. This finding is consistent with the absence of vanadium species exposed on the catalyst surface, as demonstrated in section 1 . In contrast, equimolar quantities of acetone and acetylene were obtained on the V-containing samples, which highlights that basic reactivity of $\mathrm{MBOH}$ is involved for these catalysts. Figure 8 shows the $\mathrm{MBOH}$ conversions normalized with respect to the specific surface area of V-free sample, i.e. $35 \mathrm{~m}^{2} \mathrm{~g}^{-1}$. It appears that bulk vanadium content not only influences the level of conversion of $\mathrm{MBOH}$ into acetone and acetylene, but also the $\mathrm{MBOH}$ conversion profile measured as a function of time on stream. For low vanadium contents $(x \leq 3)$, the $\mathrm{MBOH}$ conversion remains essentially constant upon time on stream. This is a common behavior for non-modified hydroxyapatites. ${ }^{[48]}$ Interestingly, for higher vanadium contents $(x \geq 4)$, the catalysts were found to deactivate with time on stream. The absence of both carbon deficit and brown coloration of the spent catalysts discards strong adsorption of products ${ }^{[52]}$ and rather points to a modification of the acid-base balance occurring upon time on stream.

As far acidic partner of the acid-base pair is concerned, it was shown in section 1 that vanadium bulk incorporation tends to decrease the concentration of available PO-H Brønsted acid sites at the benefit of $\mathrm{Ca}^{2+}$ Lewis acid sites accessibility. Recently it was shown that, while keeping constant the concentration in $\mathrm{OH}$ groups, an increase in the top surface $\mathrm{Ca}^{2+} / \mathrm{PO}-\mathrm{H}$ ratio by changing the drying conditions of HAps was detrimental to the basic $\mathrm{MBOH}$ conversion. ${ }^{[30 a]}$ If such an increase in the $\mathrm{Ca}^{2+} / \mathrm{PO}-\mathrm{H}$ ratio on the introduction of $\mathrm{V}$ in $\mathrm{HAps}$ may explain the lower $\mathrm{MBOH}$ conversion observed 
for $\mathrm{Ca}_{10}\left(\mathrm{PO}_{4}\right)_{0.78}\left(\mathrm{VO}_{4}\right)_{5.22}(\mathrm{OH})_{2}$ compared to that obtained for the $\mathrm{V}$-free sample, it cannot account for the ranking observed for the whole series of samples. Hence, the properties of the basic partner of the acid-base pair is also likely to play a decisive influence on the control of the basic conversion of $\mathrm{MBOH}$. $\mathrm{OH}^{-}$species emerging from the channels have been identified as the main basic active sites involved in the conversion of alcohol over HAps. ${ }^{[30 a, 48]}$ It was recently shown that increasing the activation temperature of HAps from 623 to $873 \mathrm{~K}$ increases the fraction of $\mathrm{O}^{2-}$ species (enhanced intensity of the shoulder contribution at $3540 \mathrm{~cm}^{-1}$ ), resulting in an increase in the basic reactivity ${ }^{[48]}$ As a constant activation temperature was used in the present study for all of the samples (experimental section), the concentration in $\mathrm{O}^{2-}$ and $\mathrm{OH}^{-}$species must be essentially affected by the vanadium incorporation into the bulk of HAps. Despite $\mathrm{O}^{2-}$ species were found to be metastable (Figure 5), part of these species are expected to remain at $413 \mathrm{~K}$ (reaction temperature of the $\mathrm{MBOH}$ reaction). As $\mathrm{O}^{2-}$ species are supposed to exhibit a stronger basic character compared to that of $\mathrm{OH}^{-}$species, an increase of the basic reactivity is expected as the content of $V$ increases in the samples. Hence, the changes induced on the acid-base properties of the HAp catalysts upon incorporation of increasing quantities of $\mathrm{V}$ (with opposite effects between the progressive relative enrichment in $\mathrm{Ca}^{2+}$ compared to $\mathrm{PO}-\mathrm{H}$, and the enrichment in $\mathrm{O}^{2-}$ compared to $\mathrm{OH}^{-}$) may account for the ranking observed for the conversion of $\mathrm{MBOH}$. For low vanadium content $(x=0.78)$, the enrichment in $\mathrm{O}^{2-}$ species compared to the $\mathrm{V}$-free sample prevails over the moderate decrease in surface PO-H groups, which would account for the slightly greater $\mathrm{MBOH}$ conversion of $\mathrm{Ca}_{10}\left(\mathrm{PO}_{4}\right)_{5.22}\left(\mathrm{VO}_{4}\right)_{0.78}(\mathrm{OH})_{2}$ compared to $\mathrm{Ca}_{10}\left(\mathrm{PO}_{4}\right)_{6}\left(\mathrm{VO}_{4}\right)_{0}(\mathrm{OH})_{2}$. At higher $\mathrm{V}$ loadings, the lower $\mathrm{MBOH}$ conversions may be attributed to the prevailing detrimental effect of calcium enrichment on the acid-base balance. These modifications of the acid-base balance are also at the origin of the deactivation process observed in the $\mathrm{MBOH}$ reaction for the more highly-loaded $\mathrm{V}$ HAp samples. Due to the metastability of the oxy-hydroxy-apatite phase formed upon dehydration inside the channels, the reversible transformation of $\mathrm{O}^{2-}$ into $\mathrm{OH}^{-}$species is likely to occur during both cooling to $413 \mathrm{~K}$ (Figure 5) and time on stream as the presence of trace amounts of water in $\mathrm{MBOH}$ could not be avoided. In the latter case, the progressive transformation of strong basic sites $\left(\mathrm{O}^{2-}\right.$ 
species) to weaker basic sites $\left(\mathrm{OH}^{-}\right.$species) could be responsible for the deactivation process. Regarding the catalysts with the lowest $V$ contents $(x \leq 3)$, the limited formation of such strong basic sites would account for the absence of deactivation with time on stream. This study puts particular emphasis on how difficult is the characterization of basicity generated at high temperature over such a catalytic system.

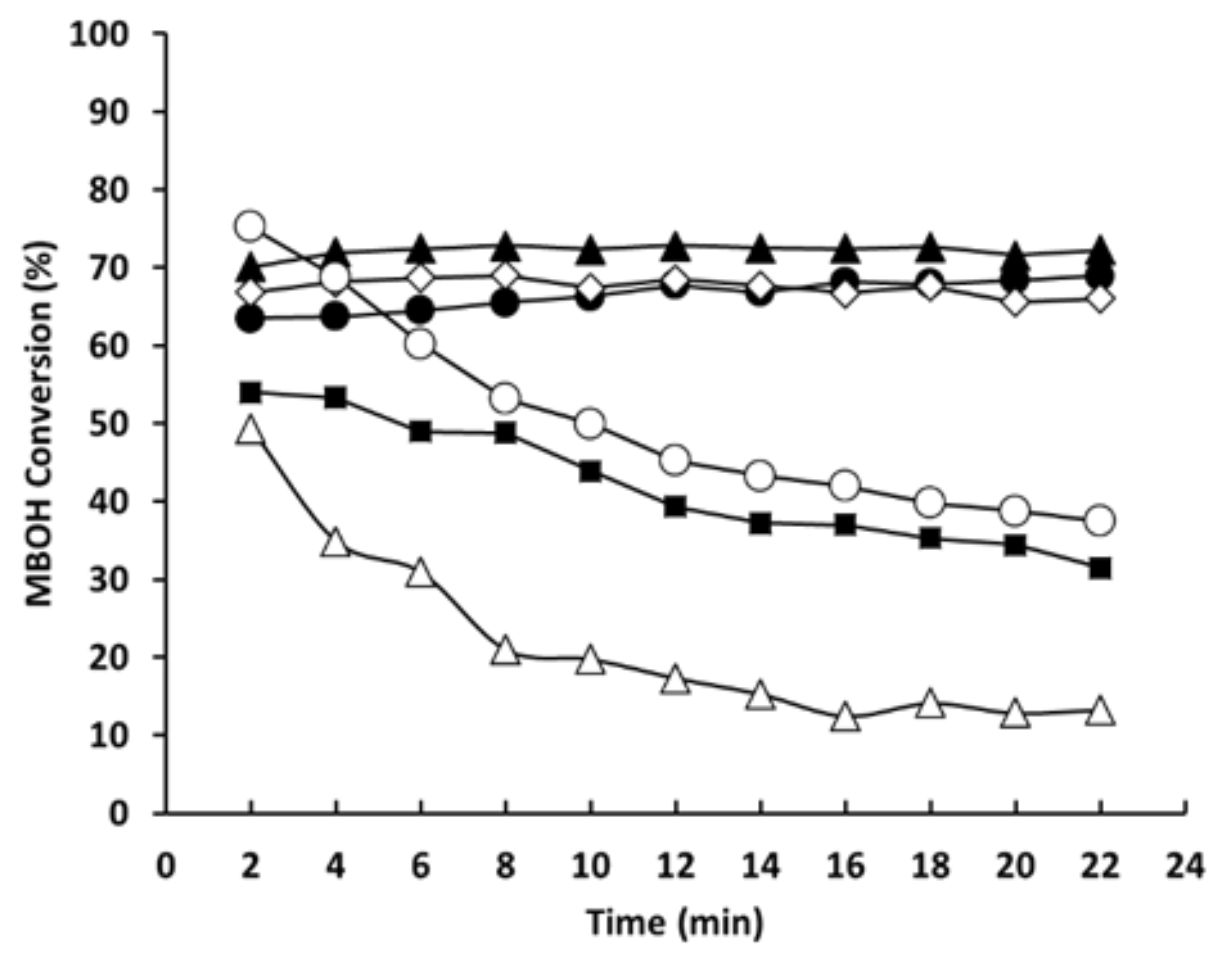

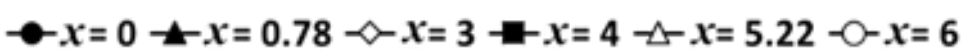

Figure 8. Influence of the substitution of phosphates by vanadates in $\mathrm{Ca}_{10}\left(\mathrm{PO}_{4}\right)_{6-x}\left(\mathrm{VO}_{4}\right)_{x}(\mathrm{OH})_{2-2 y} \mathrm{O}_{y}$ samples on the evolution with time on stream of the $\mathrm{MBOH}$ conversion normalized with the respect to the specific surface area of the $V$-free sample $\mathrm{Ca}_{10}\left(\mathrm{PO}_{4}\right)_{6}(\mathrm{OH})_{2}: 35 \mathrm{~m}^{2} \mathrm{~g}^{-1}$.

\subsection{Reactivity toward hydrogen.}

$\mathrm{H}_{2}$-TPR experiments were carried out (Figure 9) as the incorporation of vanadium is likely to confer redox properties to the apatite system. The reduction of isolated vanadium species is expected to occur at high temperatures. ${ }^{[53]}$ The TCD signals observed above $873 \mathrm{~K}$ for samples with high vanadium contents (Figure 9, $x=5.22$ and 6) are likely attributed to the reduction of isolated vanadium species 
in the HAps. More surprisingly, a TCD signal is also observed at lower temperatures for the lowlyloaded V-HAp samples and for the V-free sample. According to the analysis of the composition of the effluent gas by mass spectrometry on a V-free sample (Figure S4a), the TCD signal in the 773-1073 K range cannot be ascribed to carbonate decomposition $/ \mathrm{CO}_{2}$ desorption but unambiguously results from the concomitant production of water and consumption of $\mathrm{H}_{2}$. Whereas the release of water is consistent with a dehydration process along the $\mathrm{OH}$ columns (section 2), the consumption of $\mathrm{H}_{2}$ is rather unexpected in the absence of redox center in the material. Such a phenomenon has already been reported and ascribed to hydrogen dissociation based on the modification of the O1s core level XPS signal. ${ }^{[54]}$

Interestingly, similar signals are detected in the V-containing samples and their onset formation shifts to lower temperatures as the vanadium content increases. In the absence of vanadium and for a low vanadium content in the samples $(x=0$ and 0.55$)$, the TCD signal shows two contributions, whereas only one contribution is observed at higher vanadium contents. With the data available to date, it remains difficult to conclude on the possible overlapping of the two signals or to the progressive disappearance of the low-temperature contribution. This decrease in the temperature of $\mathrm{H}_{2}$ consumption as the $V$ content increases in the samples might be related to a modification of the surface composition with increasing $\mathrm{V}$ contents (Table 1). As described in section 2, the number of $\mathrm{OH}$ species decreases and that of $\mathrm{O}^{2-}$ species increases as the temperature increases. Given the proton conduction property described in Figure $7 \mathrm{a}$, a fraction of $\mathrm{O}^{2-}$ species may reach the surface. The DRIFT spectrum shown in Figure S4b supports the occurrence of $\mathrm{H}_{2}$ dissociation in this low-temperature range, with the observation of an IR band ascribed to $\mathrm{Ca}-\mathrm{H}$ formation (calcium hydride). Such a dissociation process should only be allowed when $\mathrm{O}^{2-}$ species, neighboring to $\mathrm{Ca}^{2+}$ sites, are available to accommodate the proton moiety issued from the heterolytic dissociation of $\mathrm{H}_{2}$ and eventually forming a surface $\mathrm{OH}^{-}$species. Bulk vanadium incorporation indirectly helps the unexpected surface reactivity for V-modified HAps by promoting both the generation of strong basic sites over the apatite system, that are required to activate $\mathrm{H}_{2}$ dissociation in the absence of any metallic function, and by 
exposing calcium-rich terminations that favor the stabilization of the hydride species. Finally, these data shed light on the fact that $\mathrm{H}_{2}$ can be used as a unique an original molecule to probe metastable strong surface basic sites generated under thermal activation that might be missed by more conventional approaches such as $\mathrm{CO}_{2}$-TPD experiment, for which $\mathrm{CO}_{2}$ adsorption on basic sites is achieved at RT, or model reactions when carried out at too low temperatures.

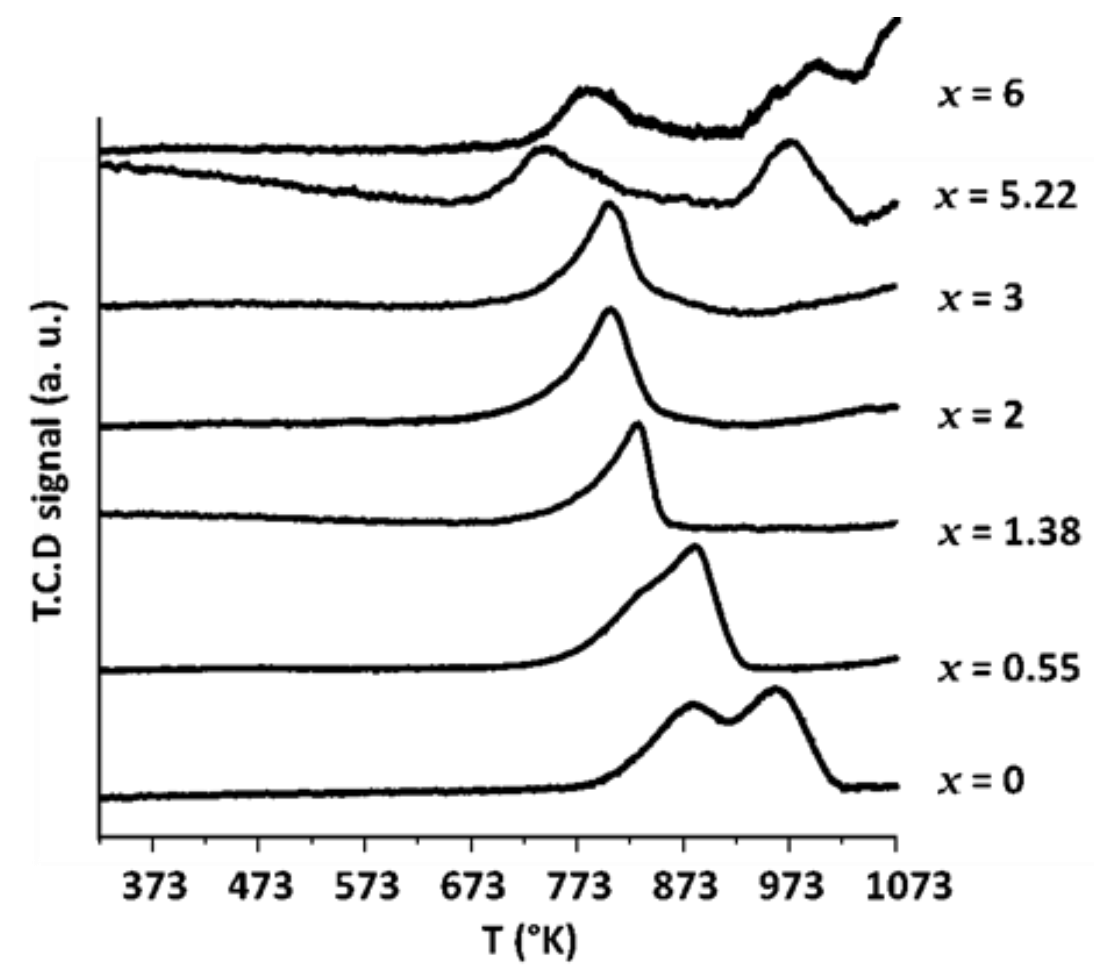

Figure 9. $\mathrm{H}_{2}$-TPR experiments for the $\mathrm{Ca}_{10}\left(\mathrm{PO}_{4}\right)_{6-x}\left(\mathrm{VO}_{4}\right)_{x}(\mathrm{OH})_{2-2 y} \mathrm{O}_{y}$ samples.

\subsection{Propane conversion in the presence of oxygen}

\section{3a Classical reactor}

Figure 10 shows the conversion of $\mathrm{C}_{3} \mathrm{H}_{8}$ and the concentrations of $\mathrm{C}_{3} \mathrm{H}_{6}$ and $\mathrm{CO}_{x}\left(\mathrm{CO}+\mathrm{CO}_{2}\right)$ as a function of the temperature and the time on stream for $\mathrm{Ca}_{10}\left(\mathrm{PO}_{4}\right)_{0.78}\left(\mathrm{VO}_{4}\right)_{5.22}(\mathrm{OH})_{1.32} \mathrm{O}_{0.34} . \mathrm{C}_{3} \mathrm{H}_{8}$ conversion increases as the reaction temperature increases with increasing formation of $\mathrm{C}_{3} \mathrm{H}_{6}$ and $\mathrm{CO}_{x}\left(\mathrm{CO}+\mathrm{CO}_{2}\right)$ as main products. Trace amounts of $\mathrm{C}_{2} \mathrm{H}_{4}$ were detected from 698 to $773 \mathrm{~K}$, whereas traces of $\mathrm{CH}_{4}$ were 
detected from 748 to $773 \mathrm{~K}$. Oxygenates such as acetone, propenal and acrolein were not detected under the present experimental conditions. Measurable amounts of $\mathrm{H}_{2}$ (Table 3) were also recorded in the $673-773 \mathrm{~K}$ temperature range. Figure 10 shows that the concentration of $\mathrm{O}_{2}$ decreases as the reaction temperature increases. It can be seen that oxygen remains over the whole temperature domain, its conversion reaching about $60 \%$ at $773 \mathrm{~K}$. Figure 10 also shows that stationary conditions are reached very quickly at each temperature showing no deactivation of the sample. The $\mathrm{C}_{3} \mathrm{H}_{6}$ selectivity was found to increase moderately as the temperature increased from 673 to $773 \mathrm{~K}$ for all the samples (Figure S5), typically from 22 to $31 \%$ for $\mathrm{Ca}_{10}\left(\mathrm{PO}_{4}\right)_{0.78}\left(\mathrm{VO}_{4}\right)_{5.22}(\mathrm{OH})_{1.32} \mathrm{O}_{0.34}$, whereas that of $\mathrm{CO}_{x}$ decreased from 78 to $67 \%$ in the same temperature range.

Figure 11 shows the influence of the substitution of the phosphates by the vanadates in the HAp samples on the conversion of $\mathrm{C}_{3} \mathrm{H}_{8}$ and the selectivity in $\mathrm{C}_{3} \mathrm{H}_{6}$ at $723 \mathrm{~K}$. The fraction of vanadates incorporated in the HAp samples exhibits little influence on the conversion of $\mathrm{C}_{3} \mathrm{H}_{8}$, which remains close to $3 \%$ for all catalysts except for the fully substituted sample $\left(\mathrm{Ca}_{10}\left(\mathrm{PO}_{4}\right)_{0}\left(\mathrm{VO}_{4}\right)_{6}(\mathrm{OH})_{2-y} \mathrm{O}_{y}\right)$ whose conversion of $\mathrm{C}_{3} \mathrm{H}_{8}$ decreases to $1.3 \%$. In contrast, the introduction of increasing amounts of $\mathrm{V}$ in the samples promotes $\mathrm{C}_{3} \mathrm{H}_{6}$ selectivity to a significant extent. The $\mathrm{C}_{3} \mathrm{H}_{6}$ selectivity thus increases from 5.4 \% for $\mathrm{Ca}_{10}\left(\mathrm{PO}_{4}\right)_{6}\left(\mathrm{VO}_{4}\right)_{0}(\mathrm{OH})_{2}$ to $26.4 \%$ for $\mathrm{Ca}_{10}\left(\mathrm{PO}_{4}\right)_{0.78}\left(\mathrm{VO}_{4}\right)_{5.22}(\mathrm{OH})_{1.32} \mathrm{O}_{0.34}$. For samples with $x$ greater than or equal to 3.0 , the $\mathrm{C}_{3} \mathrm{H}_{6}$ selectivity was found to be above $20 \%$. To avoid any bias due to differences in the specific surface area of the catalysts, the conversion of $\mathrm{C}_{3} \mathrm{H}_{8}$ was normalized on a 35 $\mathrm{m}^{2} / \mathrm{g}$ basis associated with the $x=0$ compound (Figure 11, O). $\mathrm{Ca}_{10}\left(\mathrm{PO}_{4}\right)_{0.78}\left(\mathrm{VO}_{4}\right)_{5.22}(\mathrm{OH})_{1.32} \mathrm{O}_{0.34}$ appears to be the most active catalyst in this series of samples. From Table 3, the concentrations in $\mathrm{C}_{3} \mathrm{H}_{6}$ and $\mathrm{H}_{2}$ do not follow similar trends since that in $\mathrm{H}_{2}$ decreases and becomes lower than that in propene at high vanadium content. This indicates that beside the dehydrogenation pathway to propene, the ODHP reaction also takes place. Consistently, the presence of gaseous oxygen is required to maintain a significant conversion over time on stream. When $\mathrm{O}_{2}$ is removed from the reacting feed, only residual propane conversion into propene is measured (Figure $\mathbf{S 6}$ and Table $\mathbf{S 6}$ ), which is a typical behavior reported earlier for ODH reactions. ${ }^{[16 d, 55]}$ In addition, in a separate set of experiments, the $\mathrm{O}_{2}$ 
concentration was increased at various temperatures on $\mathrm{Ca}_{10}\left(\mathrm{PO}_{4}\right)_{0.78}\left(\mathrm{VO}_{4}\right)_{5.22}(\mathrm{OH})_{1.32} \mathrm{O}_{0.34}$ (data not shown) and it was found that this did not result in any significant change in $\mathrm{C}_{3} \mathrm{H}_{8}$ conversion and $\mathrm{C}_{3} \mathrm{H}_{6}$ selectivity, suggesting that catalyst reoxidation is not the rate determining step of the ODHP reaction, as also reported in earlier studies carried out for various catalysts when considering a Mars and Van Krevelen mechanism. ${ }^{[13,15,56]}$

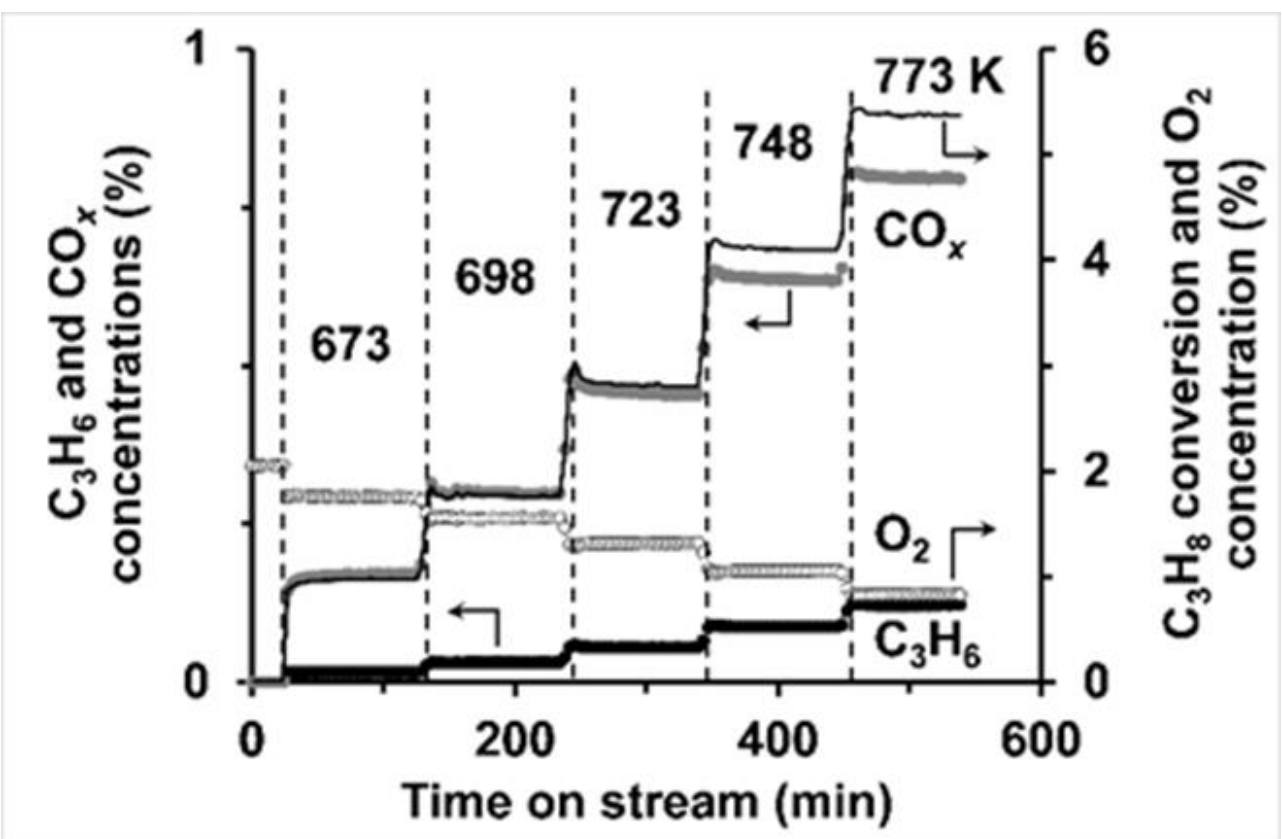

Figure 10. Evolution of the conversion of $\mathrm{C}_{3} \mathrm{H}_{8}(-)$ and the concentrations in $\mathrm{C}_{3} \mathrm{H}_{6}(-), \mathrm{O}_{2}(\mathrm{O})$ and $\mathrm{CO}_{x}$ (๑) $\left(7.4 \% \mathrm{C}_{3} \mathrm{H}_{8}, 2.2 \% \mathrm{O}_{2}\right.$ in $\mathrm{He}, 12.5 \mathrm{~mL}_{\mathrm{NTP}} \mathrm{min}^{-1}$ total flow) as a function of time on stream and reacting temperature on $100 \mathrm{mg}$ of $\mathrm{Ca}_{10}\left(\mathrm{PO}_{4}\right)_{0.78}\left(\mathrm{VO}_{4}\right)_{5.22}(\mathrm{OH})_{1.32} \mathrm{O}_{0.34}$. 


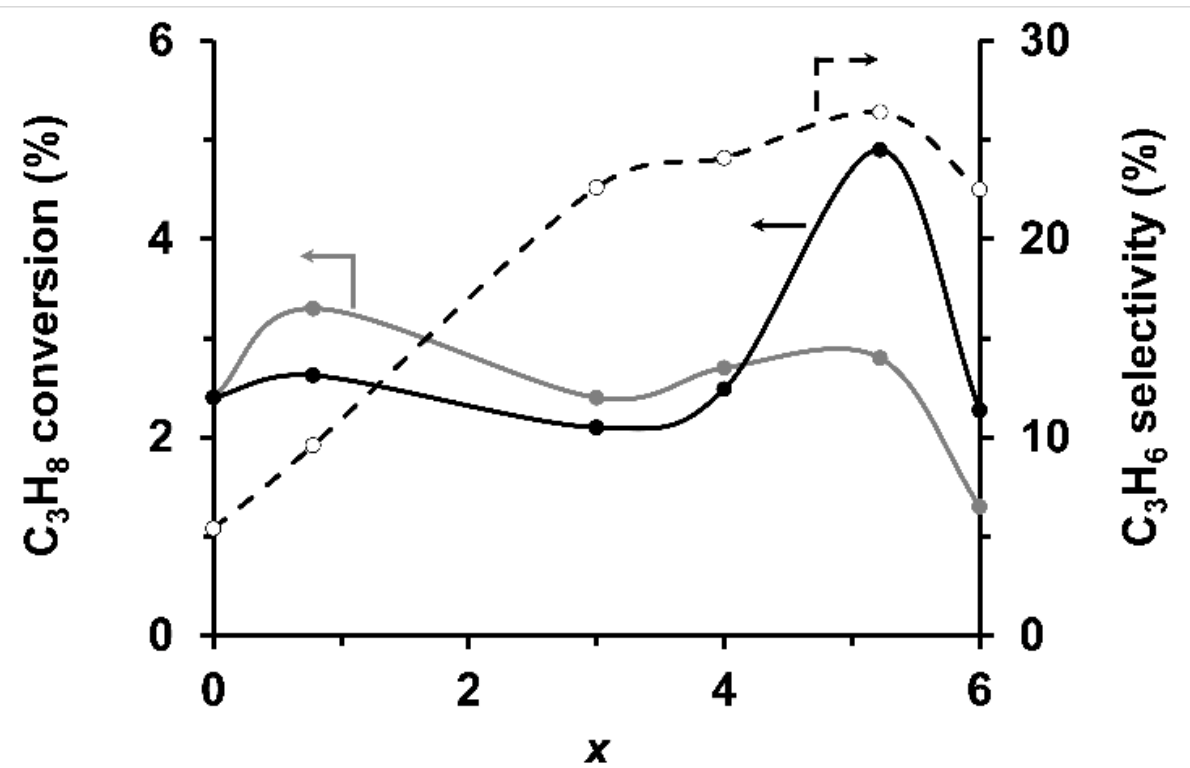

Figure 11. Influence of the substitution of phosphates by vanadates of $\mathrm{Ca}_{10}\left(\mathrm{PO}_{4}\right)_{6-x}\left(\mathrm{VO}_{4}\right)_{x}(\mathrm{OH})_{2-y} \mathrm{O}_{y}$ samples on $\mathrm{C}_{3} \mathrm{H}_{8}$ conversion (o), $\mathrm{C}_{3} \mathrm{H}_{8}$ conversion normalized with respect to the specific surface area of the V-free sample $\left(\mathrm{Ca}_{10}\left(\mathrm{PO}_{4}\right)_{6}\left(\mathrm{VO}_{4}\right)_{0}(\mathrm{OH})_{2}: 35 \mathrm{~m}^{2} / \mathrm{g}\right)(\mathrm{O})$ and $\mathrm{C}_{3} \mathrm{H}_{6}$ selectivity $(\mathrm{O})\left(7.4 \% \mathrm{C}_{3} \mathrm{H}_{8}, 2.2 \% \mathrm{O}_{2}\right.$ in $\mathrm{He}, 12.5 \mathrm{~mL}_{\mathrm{NTP}} \mathrm{min}^{-1}$ total flow) at $723 \mathrm{~K}$.

Table 3. : $\mathrm{C}_{3} \mathrm{H}_{6}$ and $\mathrm{H}_{2}$ concentrations measured in the catalytic reaction $\left(7.4 \% \mathrm{C}_{3} \mathrm{H}_{8}, 2.2 \% \mathrm{O}_{2}\right.$ in $\mathrm{He}, 12.5$ $\mathrm{mL}_{\text {NTP }} \mathrm{min}^{-1}$ total flow) at $723 \mathrm{~K}$ as a function of the vanadium content in the $\mathrm{Ca}_{10}\left(\mathrm{PO}_{4}\right)_{6-x}\left(\mathrm{VO}_{4}\right)_{x}(\mathrm{OH})_{2-}$ ${ }_{y} \mathrm{O}_{\mathrm{y}}$ series

\begin{tabular}{lcc}
\hline Nominal vanadium & \multicolumn{2}{l}{ Concentration (ppm) } \\
content $x$ & $\mathrm{C}_{3} \mathrm{H}_{6}$ & $\mathrm{H}_{2}$ \\
\hline 0 & 112 & 753 \\
0.78 & 250 & 1213 \\
3.00 & 425 & 742 \\
4.00 & 474 & 662 \\
5.22 & & \\
& 578 & 458 \\
6.00 & 230 & 165 \\
\hline
\end{tabular}




\section{$\underline{3.3 b}$ lonic conduction measured under operando and in situ wet neutral conditions}

In the Mars and Van Krevelen mechanism, the rapid reoxidation of the catalyst was proposed to be assisted by the diffusion of bulk oxygen anions. ${ }^{[13 a, 15,57]}$ The conductivity data recorded under an inert atmosphere on $\mathrm{Ca}_{10}\left(\mathrm{PO}_{4}\right)_{0.78}\left(\mathrm{VO}_{4}\right)_{5.22}(\mathrm{OH})_{2}$ (section 2.2.b, Figures 6 and S2) show that the mobility of $\mathrm{O}^{2-}$ species is activated above $873 \mathrm{~K}$. The latter temperature is thus found to be much greater than the temperatures for which the catalytic reaction proceeds. Since the atmosphere under which the conductivity measurements are performed is likely to influence the conduction process, ${ }^{[7 c, 42]}$ a second set of impedance spectroscopy measurements was performed under atmospheres of increasing complexity and ultimately under the catalytic reaction conditions. The ionic conductivity firstly measured under the pre-treatment $\left(\mathrm{O}_{2}-\mathrm{He}\right)$ gas composition was found to remain essentially constant at $773 \mathrm{~K}$, confirming that the sample was stable under these conditions. After cooling to $673 \mathrm{~K}$, the pellet was exposed to the reacting feed at 673, 723 and 773K (Figure 12a). The activation energy obtained in this temperature range ( $0.13 \mathrm{eV}$ from the corresponding Arrhenius plot in Figure 12b) was found to be similar to that obtained under an inert atmosphere (Figure S3b). This low activation energy does not support the diffusion of $\mathrm{O}^{2-}$ ions in the apatite structure during the ODHP catalytic reaction. The absence of long range mobility of $\mathrm{O}^{2-}$ species, as however often reported for the Mars and Van Krevelen mechanism, rather suggests a rapid reoxidation process of the catalyst taking place exclusively on the surface. In contrast, these operando measurements indicate that proton mobility preferentially occurs according to a Grotthus mechanism during the catalytic reaction. In addition, despite the lower $\mathrm{C}_{3} \mathrm{H}_{8}$ conversion measured in the conductivity set-up compared to that obtained in the classical catalytic reactor, which can be merely ascribed to the density of the pellet compared to the powdered sample in the classical reactor, Figure 12a shows that the ionic conductivity of the working catalyst was significantly increased under the reaction conditions compared to the pretreatment ones. 
It was also reported that the presence of water in the gaseous atmosphere may influence the conductivity process to a significant extent in the hydroxyapatite material. ${ }^{[2 i, 7 c, 42]}$ In order to evaluate whether the enhanced proton conduction described in Figure 12a could be only attributed to the presence of the water being produced during the ODHP reaction, a third set of experiments was carried out to compare the ionic conductivity measured at 723 and $773 \mathrm{~K}$ under dry and wet He feeds with water contents representative of those achieved under the catalytic reaction conditions at the same temperatures. Figure $12 \mathrm{c}$ shows that the ionic conductivity does not vary to a significant extent in the absence and in the presence of water in the feed. This confirms that water is not a carrier for protons and that the diffusion of protons must be essentially due to the formation / scission of $\mathrm{O}-\mathrm{H}$ bonds along the $c$-axis from the bulk to the surface of the material. The lack of influence of water on the ionic conductivity (Figure 12c) clearly shows that the much higher ionic conductivity under reaction conditions compared to the $\mathrm{O}_{2}$-He atmosphere (Figure 12a) can be ascribed to the involvement of the catalytic reaction in itself. Hence, the surface catalytic reaction should be responsible for an increase in the mobility of protons in the apatite structure. This important and very original finding is discussed in the next section aiming at rationalizing the operating mode of this catalytic system in the ODHP reaction. 

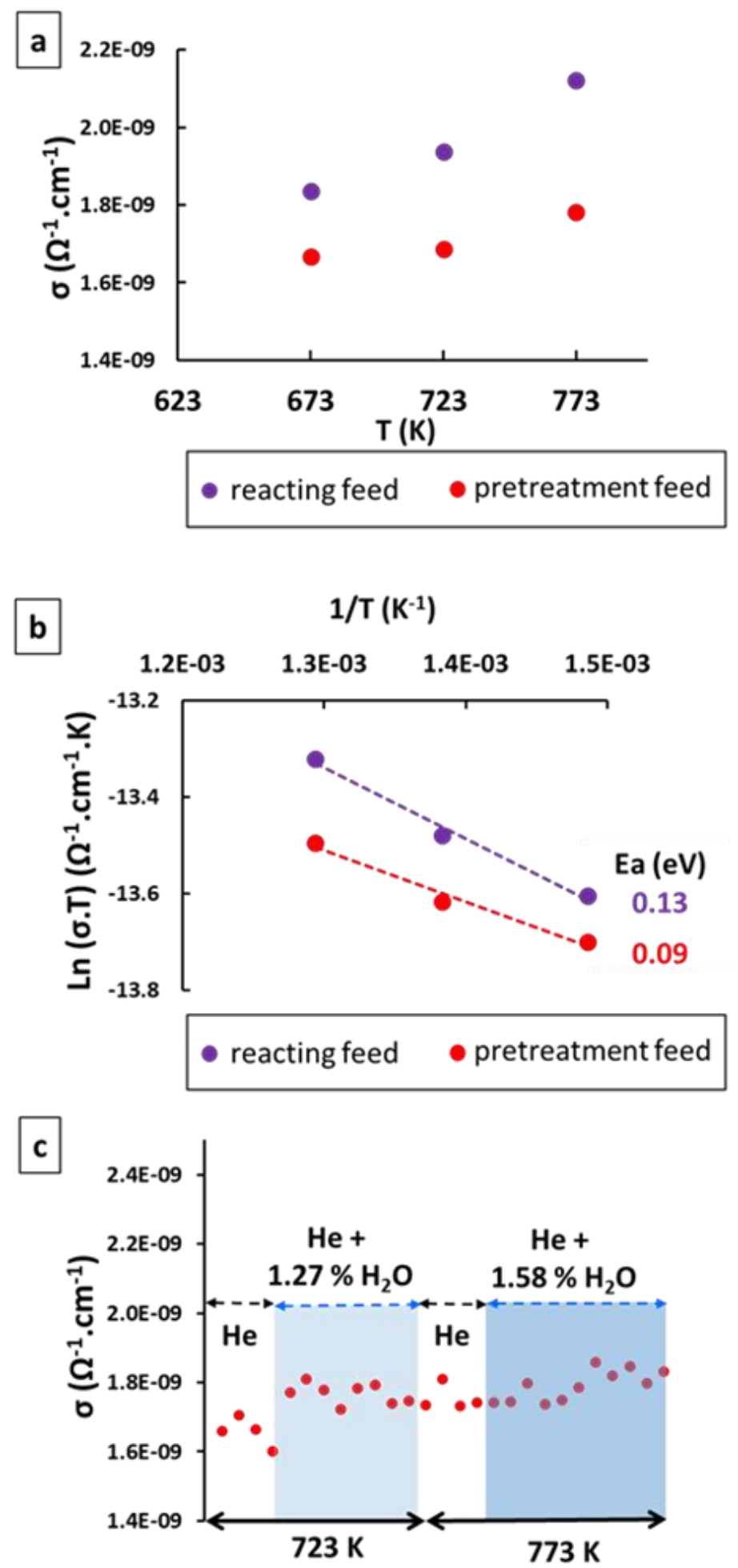

Figure 12. : (a) Ionic conductivity of $\mathrm{Ca}_{10}\left(\mathrm{PO}_{4}\right)_{0.78}\left(\mathrm{VO}_{4}\right)_{5.22}(\mathrm{OH})_{2}$ measured as a function of the temperature under the pretreatment gas composition $\left(\mathrm{O}_{2}-\mathrm{He}\right)$ and under catalytic reaction conditions, (b) Arrhenius plots for the ionic conductivity of $\mathrm{Ca}_{10}\left(\mathrm{PO}_{4}\right)_{0.78}\left(\mathrm{VO}_{4}\right)_{5.22}(\mathrm{OH})_{2}$ under pretreatment $\left(\mathrm{O}_{2}-\mathrm{He}\right)$ and reacting feeds $(\mathrm{c})$ lonic conductivity of $\mathrm{Ca}_{10}\left(\mathrm{PO}_{4}\right)_{0.78}\left(\mathrm{VO}_{4}\right)_{5.22}(\mathrm{OH})_{2}$ measured at 723 and $773 \mathrm{~K}$ under dry He flow and wet He flow (1.3 and $1.6 \%$ of $\mathrm{H}_{2} \mathrm{O}$ in He at 723 and $773 \mathrm{~K}$, respectively, to mimic the water contents produced in the course of the ODHP catalytic reaction). 


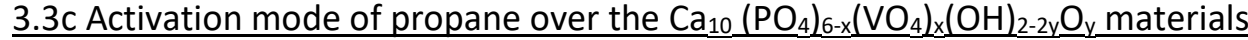

It may appear disappointing that an increasing incorporation of vanadium in the $\mathrm{Ca}_{10}\left(\mathrm{PO}_{4}\right)_{6}$ ${ }_{x}\left(\mathrm{VO}_{4}\right)_{x}(\mathrm{OH})_{2-2 y} \mathrm{O}_{y}$ solid solutions does not result in a significant improvement in propane conversion (except for the maximum in $\mathrm{C}_{3} \mathrm{H}_{8}$ conversion observed for $\left.\mathrm{Ca}_{10}\left(\mathrm{PO}_{4}\right)_{0.78}\left(\mathrm{VO}_{4}\right)_{5.22}(\mathrm{OH})_{1.32} \mathrm{O}_{0.34}\right)$. The data obtained within the V-modified solid solution series may, nevertheless, help revisit a key step in the activation mode of propane. Contrary to the reoxidation step that is not kinetically determinant, the main limitation of the ODHP reaction is the selective activation of propane. This illustrates how challenging it is to convert propane, while avoiding its over-oxidation to $\mathrm{CO}_{2}$. Based on the surface characterizations reported in the present study (section 1), the moderate influence of vanadium content on the conversion of $\mathrm{C}_{3} \mathrm{H}_{8}$ should be ascribed to the limited exposure of vanadium species on the top surface, which suggests that propane activation should be intrinsic to the HAp system.

In the case of vanadium oxy-hydroxy-apatite solid solutions, the vanadium species promote the formation of native defects in the $\mathrm{OH}^{-}$channels resulting in lower concentrations in $\mathrm{OH}^{-}$in the asprepared catalysts (Figure 4), and in particular for $\mathrm{Ca}_{10}\left(\mathrm{PO}_{4}\right)_{0.78}\left(\mathrm{VO}_{4}\right)_{5.22}(\mathrm{OH})_{1.32} \mathrm{O}_{0.34}$ that is found to be the most active catalyst for the production of propene. The presence of $\mathrm{V}$ also helps the generation of additional $\mathrm{O}^{2-}$ species by thermally-activated dehydration. Before reaction, the sample was activated at $773 \mathrm{~K}$ indeed, and this activation temperature is higher than the onset temperature of observation of the $3530-3520 \mathrm{~cm}^{-1}$ shoulder contribution that indirectly probes the formation of $\mathrm{O}^{2-}$ species (Figure 5). Moreover, this activation temperature is higher than the temperature at which proton mobility (Figure 7) becomes activated (Figure 6) and it must be recalled that the proton mobility process leads eventually to the exposure of the $\mathrm{O}^{2-}$ species on the top surface. Despite the observed metastable character of the $\mathrm{O}^{2-}$ species, these species are stable at high temperatures and basic enough to allow for the heterolytic dissociation of hydrogen thanks to the close proximity of $\mathrm{Ca}^{2+}$ cations. Similarly, the high operating temperatures used for the catalytic reaction (673 to $773 \mathrm{~K}$ after activation at $773 \mathrm{~K}$ ) favor a higher proportion of $\mathrm{O}^{2-}$ sites at the expense of that of the $\mathrm{OH}^{-}$groups and also provide stability 
of the catalyst over time on stream, as illustrated by the absence of deactivation reported in Figure $\mathbf{1 1 .}$ It is thus proposed that these $\mathrm{O}^{2-}$ species emerging from the $\mathrm{OH}$ channels would be involved in the activation process of propane. This proposal is supported by the highest $\mathrm{C}_{3} \mathrm{H}_{8}$ conversion observed for $\mathrm{Ca}_{10}\left(\mathrm{PO}_{4}\right)_{0.78}\left(\mathrm{VO}_{4}\right)_{5.22}(\mathrm{OH})_{1.32} \mathrm{O}_{0.34}$, which also exhibits the highest initial content in $\mathrm{O}^{2-}$ as indicative of its peculiar ability to shift the $\mathrm{OH}^{-} \longrightarrow \mathrm{O}^{2-}$ equilibrium toward the formation of higher concentration of active $\mathrm{O}^{2-}$ species under thermal activation and catalytic conditions. Even if this may appear as controversial, ${ }^{[13 b, 17]}$, such a C-H bond heterolytic activation has been already proposed in literature, ${ }^{[16 a,}$ ${ }^{18]}$ in relation with the involvement of strongly nucleophilic species ${ }^{[13 a, 16 e, 58]}$ or strong basic sites. ${ }^{[58 b]}$. Although not explicitly proposed in the case of the $\mathrm{VMgO}$ reference system, it is important to note that better catalytic performance was obtained when the catalyst was prepared in the presence of an excess of $\mathrm{MgO}^{[19 a, 58 b]}$ although the $\mathrm{Mg}_{2} \mathrm{~V}_{2} \mathrm{O}_{7}$ phase was claimed to be the active phase. ${ }^{[16 \mathrm{~d}, 59]}$ The increase in the catalyst basicity was also proposed to promote the desorption of propene. ${ }^{[19 c, 21]}$ In the present work, the increase in basicity of the studied materials may also be responsible for the slight increase in propene selectivity observed with increasing vanadium content (Figure 11) and increasing reaction temperature (Figure S5).

\section{$\underline{3.3 d \text { Propane conversion mechanism assisted by proton migration. }}$}

This study emphasizes that the active phase is the vanadium oxy-hydroxy-apatite formed at high temperatures. Besides the key role played by the $\mathrm{O}^{2-}$ surface emerging from the $\mathrm{OH}$ channels in the $\mathrm{C}$ $\mathrm{H}$ bond activation process, vanadium incorporation was also found to increase the propene selectivity to a significant extent (Figure 11). The active site is thus proposed to involve two types of surface oxygen: (i) a basic/nucleophilic $\mathrm{O}^{2-}$ species close to a $\mathrm{Ca}^{2+}$ cation and (ii) a labile $\mathrm{O}^{2-}$ species from a $\mathrm{VO}_{4}$ tetrahedron $\left(\left(\mathrm{O}^{2-}\right)_{3} \mathrm{~V}^{5+} \mathrm{O}^{2-}\right)$ that controls the propene selectivity. As depicted in the catalytic cycles in Figure 13, it is proposed that the catalytic reaction is assisted by the proton mobility that helps the generation of the surface $\mathrm{O}^{2-}$ species (la) acting as strong basic sites and enabling the proton abstraction from a C-H bond of propane (Ib). The presence of surface $\mathrm{Ca}^{2+}$ sites neighboring to the $\mathrm{O}^{2-}$ 
species interacting with the propane adduct may help stabilize the hydride species formed with the production of propene and should favor the desorption of propene (Ic). The transient formation of a $\mathrm{Ca}^{2+}-\mathrm{H}^{-} / \mathrm{O}^{2-}-\mathrm{H}^{+}$intermediate (Ic) may account for the amounts of gaseous $\mathrm{H}_{2}$ measured during the catalytic reaction, especially for lowly vanadium loaded catalysts. However, as shown above (section 3.3a), the formation of propene cannot be attributed exclusively to propane dehydrogenation (Table 3, S4) and the additional oxidative dehydrogenation parallel route is clearly involved and is found to be promoted as the vanadium incorporation increases. Indeed, it has been checked that removing $\mathrm{O}_{2}$ from the reacting feed was found to lead to a rapid and drastic decrease in the production of propene indeed, whereas this product was formed continually and in significant quantities in the presence of $\mathrm{O}_{2}$ (Figure 10, Figure S6).

The transient surface protonation of the $\mathrm{O}^{2-}$ species into $\mathrm{OH}^{-}$species (Ic) (resulting from the $\mathrm{C}-\mathrm{H}$ activation (Ib)) further enhances the dynamic interconversion of surface $\mathrm{OH}^{-} \rightarrow \mathrm{O}^{2-}$ by the proton migration process (Id), as supported by the intensification of the mobility of proton in the apatite structure observed under reaction conditions (Figure 12a). This proton migration process not only regenerates the $\mathrm{O}^{2-}$ activation site but it also allows the protonation of vanadate groups. Indeed, according to earlier studies, ${ }^{[27 c, 46 a]}$ due to lower involved distances, the proton migration pathway preferentially implies neighboring phosphate groups (vanadate groups in our case) over a direct jump to the next distant $\mathrm{O}^{2-}$ species inside the channels. Such a hydroxyl group of the $\mathrm{V}$-OH species could recombine with the neighboring hydride species, leading to the release of water and to the reduction of the vanadium center (le) as predicted by DFT calculations for monomeric vanadate. ${ }^{[17 b]}$ Finally, the latter species could be rapidly reoxidised by gaseous oxygen, thus regenerating the catalytic site. 


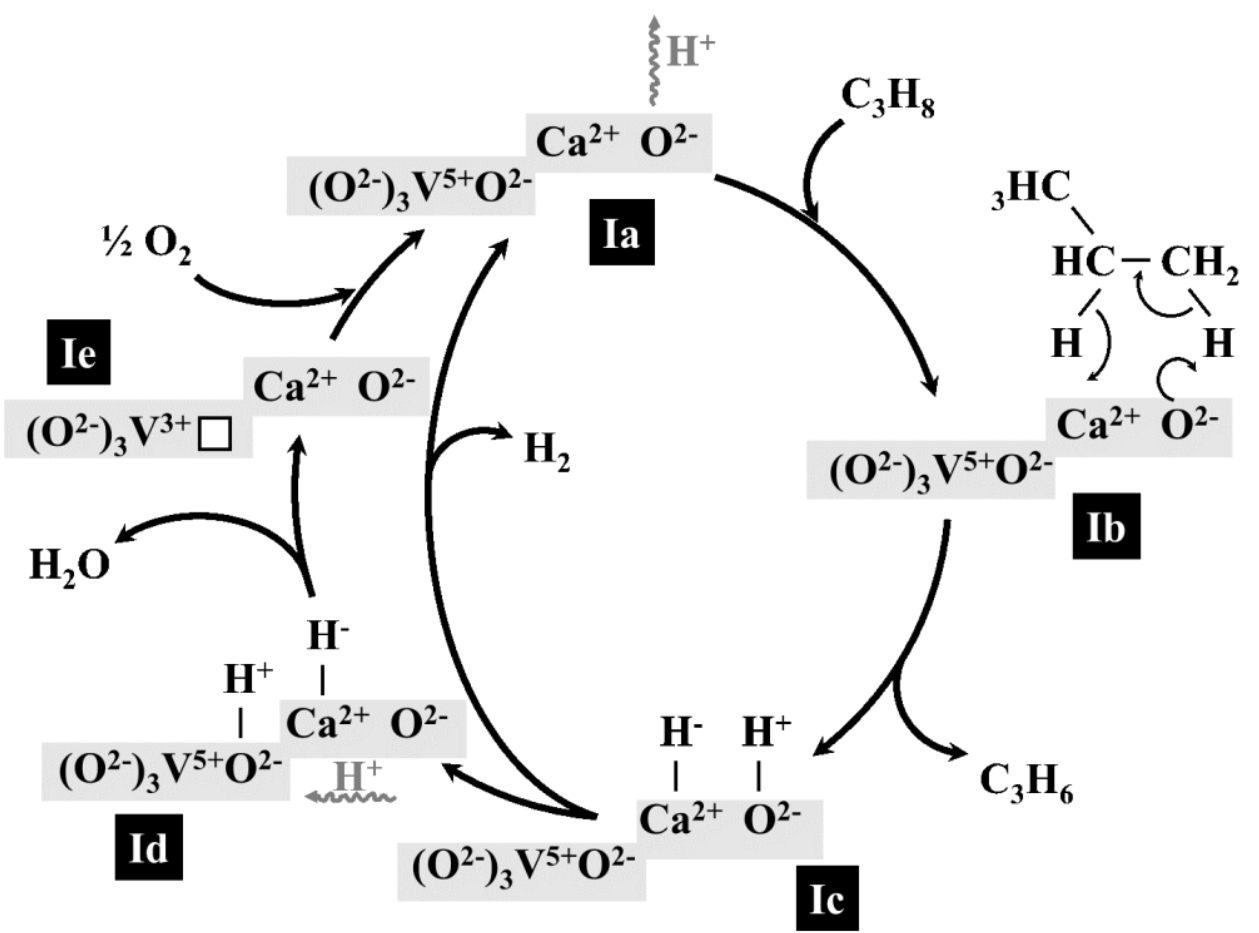

Figure 13. Schematized representation of the catalytic transformation of propane to propene involving dehydrogenation and oxidative dehydrogenation routes on $\mathrm{V}$-HAp samples exhibiting $\mathrm{Ca}^{2+}-\mathrm{O}^{2-}$ surface acid-base pairs generated thanks to proton migration process that are close to $\mathrm{VO}_{4}$ tetrahedra. The square box represents an oxygen vacancy and mm refers to the proton migration process.

\section{Conclusions}

The catalytic performance of a series of stoichiometric vanadium-substituted HAps is investigated for the catalytic conversion of propane to propene. Whereas an increase in the vanadium content is found to promote propene selectivity, it scarcely impacts the conversion in propane (except in the case of $\left.\mathrm{Ca}_{10}\left(\mathrm{PO}_{4}\right)_{0.78}\left(\mathrm{VO}_{4}\right)_{5.22}(\mathrm{OH})_{2}\right)$. This is in line with the surface deficiency in vanadium (and the absence of vanadyl species): as the bulk vanadium content increases, $\mathrm{PO}-\mathrm{H}$ rich terminations are progressively replaced by $\mathrm{Ca}^{2+}$ ones while vanadium is preferentially relaxed in the inner surface. Accordingly no vanadium acidity can be observed by adsorption of the $\mathrm{CO}$ probe molecule and the $\mathrm{MBOH}$ model reaction. Vanadium incorporation is, however, responsible for the promotion of bulk intrinsic structural properties that eventually participate to the control of the surface reactivity. Firstly, as emphasized by ${ }^{1} \mathrm{H}$ NMR, vanadium bulk incorporation is found to increase the number of native defects associated with a lack of protons inside the $\mathrm{OH}$ columns. Secondly, the formation of the vanadium oxy- 
hydroxy-apatite $\mathrm{Ca}_{10}\left(\mathrm{PO}_{4}\right)_{6-x}\left(\mathrm{VO}_{4}\right)_{x}(\mathrm{OH})_{2-2 y} \mathrm{O}_{y}$ solid solution is favored upon thermal treatment thanks partial dehydration along the $\mathrm{OH}$ columns. This latter phase is thought to be the active phase for the propane to propene conversion reaction. Thirdly, the resulting defects generate additional $\mathrm{O}^{2-}$ oxide ions responsible for the activation of anisotropic ionic conductivity along the columns. The Grotthus mechanism involved in the ionic conductivity process proceeds via the successive formation and scission of $\mathrm{O}-\mathrm{H}$ bonds with the involvement of $\mathrm{H}$-bonding interaction, as evidenced by in situ DRIFT spectroscopy. Such a proton migration process eventually results in the exposure of surface $\mathrm{O}^{2-}$ species that are likely to act as strong basic sites depending on the operating conditions. Due to the metastability of such $\mathrm{O}^{2-}$ species at moderated temperatures, the evaluation of their basicity is not straightforward, as illustrated by the deactivation observed for the basic $\mathrm{MBOH}$ conversion at $413 \mathrm{~K}$ that can be ascribed to the protonation of the $\mathrm{O}^{2-}$ species into $\mathrm{OH}^{-}$species of weaker basicity. In contrast, these $\mathrm{O}^{2-}$ species are found to be stable at high temperatures (DRIFT data), and basic enough to dissociate $\mathrm{H}_{2}$ on $\mathrm{Ca}^{2+}-\mathrm{O}^{2-}$ pairs (DRIFT data obtained after $\mathrm{H}_{2}$-TPR) and to extract a proton from a C$\mathrm{H}$ bond of propane. The key role of the strong basic $\mathrm{O}^{2-}$ ions provided by the oxy-hydroxy-apatite phase in the activation of propane is supported by the unique synergistic effect between the propane to propene catalytic reaction and the proton mobility process evidenced by operando impedance spectroscopy. As depicted in Figure 13, the transformation of propane to propene proceeds both upon oxidative dehydrogenation $\left(\mathrm{O}_{2}\right.$ is required for propene formation), and dehydrogenation routes. Two types of surface oxygen species are involved in the ODHP reaction catalytic cycle: (i) a basic $\mathrm{O}^{2-}$ species emerging from the $\mathrm{OH}$ channels of the apatite framework and (ii) a labile oxygen from the $\mathrm{VO}_{4}$ tetrahedra. The former species is formed and regenerated upon the assistance of the peculiar proton conduction ability of the apatite material. The latter species can be protonated by proton diffusion and can contribute to the formation/desorption of a water molecule. This oxygen species is eventually regenerated by oxidation with gaseous oxygen.

Such an atypical behavior provides an original example of structure sensitive catalysis with the control of surface reactivity assisted by bulk physical property. This study also suggests a modified version of 
the Mars and Van Krevelen mechanism involved for the ODHP route. As depicted in Figure 13, the ODHP catalytic cycle does not involve $\mathrm{O}^{2-}$ species diffusion in the bulk of the oxide, as is the case in the traditional Mars and Van Krevelen mechanism, but proton mobility. Finally, the vanadium oxy-hydroxyapatite system also puts emphasis on the key role of strong basic sites in the $\mathrm{C}-\mathrm{H}$ bond activation of propane.

\section{Experimental Section}

\section{Sample synthesis}

A series of vanadium-modified hydroxyapatite samples $\left(\mathrm{Ca}_{10}\left(\mathrm{PO}_{4}\right)_{6-x}\left(\mathrm{VO}_{4}\right)_{x}(\mathrm{OH})_{2}\right.$, solid solutions with $\mathrm{x}$ $=0-6)$ was prepared according to the co-precipitation procedure described previously, using an automated reactor (Optimax 1001 synthesis workstation from Mettler Toledo).60 A Ca( $\left.\mathrm{NO}_{3}\right)_{2}$ (Sigma Aldrich $\geq 99.0 \%$ ) aqueous solution, which $\mathrm{pH}$ was adjusted to 10 , was heated up to $353 \mathrm{~K}$. A second aqueous solution containing $\mathrm{NH}_{4} \mathrm{VO}_{3}$ (Sigma Aldrich $\geq 99.0 \%$ ) and $\left(\mathrm{NH}_{4}\right) \mathrm{H}_{2} \mathrm{PO}_{4}$ (Acros, 99.9\%) of appropriate concentrations was adjusted to $\mathrm{pH} 10$ and added dropwise $(2.2 \mathrm{ml} / \mathrm{min})$ to the calcium nitrate aqueous solution under reflux, with a stirring rate of $400 \mathrm{rpm}$ and under $\mathrm{N}_{2}$ flow to limit the carbonation of the materials. The $\mathrm{pH}$ was maintained at a value of 9 by continuous addition of $\mathrm{NH}_{4} \mathrm{OH}$ (0.1 $\left.\mathrm{mol} \mathrm{L}^{-1}\right)$ during the whole precipitation step. After aging for $4 \mathrm{~h}$, the washed precipitate was dried overnight at $373 \mathrm{~K}$, thermally treated under $\operatorname{Ar}\left(150 \mathrm{~mL} \mathrm{~min}^{-1}\right)$ up to $773 \mathrm{~K}\left(5 \mathrm{~K} \mathrm{~min}^{-1}\right)$ and maintained at this temperature for $90 \mathrm{~min}$. As detailed in ref. ${ }^{[26]}$, it was previously shown from XRD-Rietveld refinement, ${ }^{31} \mathrm{P}$ and ${ }^{51} \mathrm{~V}$ NMR that these samples exhibit pure crystalline hydroxyapatite structure in which the vanadate groups substituted the phosphate ones in the whole $\left.\mathrm{Ca}_{10}\left(\mathrm{PO}_{4}\right)_{6-x}\left(\mathrm{VO}_{4}\right)_{x}(\mathrm{OH})_{2}\right)$ composition range $(x=0-6)$. 


\section{Characterizations}

Prior to $\mathrm{N}_{2}$ sorption measurements, the samples were outgassed at $573 \mathrm{~K}$ overnight. The specific surface areas, calculated from the BET method, were found to vary from 20 to $44 \mathrm{~m}^{2} \mathrm{~g}^{-1}$ (Table 1).

Chemical analyses were performed by inductively-coupled plasma atomic emission spectroscopy (ICPAES, CREALINS).

XP (X-ray Photoelectron) spectra were collected on a SPECS PHOIBOS 100-5MCD photoelectron spectrometer. Monochromated Al K $\alpha(\mathrm{hv}=1486.6 \mathrm{eV})$ radiation source having a $300 \mathrm{~W}$ electron beam power was used for analysis. The emission of photoelectrons from the sample was analyzed at a takeoff angle of $90^{\circ}$ under ultra-high vacuum conditions $\left(1 \times 10^{-8} \mathrm{~Pa}\right)$. Photoelectrons were collected at a pass energy of $20 \mathrm{eV}$ with $0.1 \mathrm{eV}$ steps for $\mathrm{C}_{1 \mathrm{~s}}, \mathrm{O}_{1 \mathrm{~s}}, \mathrm{~V}_{2 \mathrm{p}}, \mathrm{Ca}_{2 \mathrm{p}}$ and $\mathrm{P}_{2 \mathrm{p}} \mathrm{XPS}$ core levels. After data collection, the binding energies were calibrated with respect to the binding energy of the $C_{1 s}$ peak at $284.7 \mathrm{eV}$. The peak areas were determined after subtraction of a Shirley background. The atomic ratio calculations were performed after normalization using Scofield factors. Spectrum processing was carried out using the Casa XPS software package.

CO adsorption-desorption experiments monitored by FTIR were performed to identify the nature of the acid sites exposed on the top surface. FTIR spectra were obtained from self-supported pellets (20$25 \mathrm{mg}, 16 \mathrm{~mm}$ diameter) placed in a borosilicate cell equipped with $\mathrm{CaF}_{2}$ windows and connected to a vacuum line allowing thermal treatments and adsorption-desorption experiments to be carried out in situ. Spectra were recorded using a Bruker Vertex 70 FTIR spectrometer, equipped with a MCT detector (resolution $2 \mathrm{~cm}^{-1}, 64$ scans per spectrum). All the spectra related to $\mathrm{CO}$ adsorption are reported in absorbance, after subtraction of the spectra of the sample before $\mathrm{CO}$ adsorption. To avoid the reduction of the $\mathrm{V}^{5+}$ species, the pellets were firstly pre-treated at $723 \mathrm{~K}\left(5 \mathrm{~K} \mathrm{~min}^{-1}\right)$ under an oxygen flow ( $30 \mathrm{~mL} \mathrm{~min}^{-1}$ ) and kept at this temperature for $2 \mathrm{~h}$, before being cooled down to $573 \mathrm{~K}$ and finally evacuated at this temperature to reach a residual pressure $\sim 1.3310^{-4} \mathrm{~Pa}$. The wafers were then transferred to the IR beamline and cooled down to about $100 \mathrm{~K}$ with liquid nitrogen. A pulse of $0.9 \mathrm{x}$ 
$10^{-6} \mathrm{~mol} \mathrm{He}$ was introduced to favor the thermal conductivity and ensure stabilization of the temperature. A first series of spectra were recorded at $100 \mathrm{~K}$ before and after introduction of increasing doses of $\mathrm{CO}$ (up to $4.0 \times 10^{-6} \mathrm{~mol}$ of $\mathrm{CO}$ ). Once the saturation of the surface by $\mathrm{CO}$ was achieved (equilibrium pressure of $133 \mathrm{~Pa}$ ), a second series of spectra was recorded during an evacuation step that was carried out for 2 hours until a residual pressure of about $210^{-2} \mathrm{~Pa}$ was reached.

${ }^{1} \mathrm{H}$ direct polarization (DP) MAS NMR spectra were recorded with a Bruker Avance 500 spectrometer and $4 \mathrm{~mm}$ zirconia rotors (spinning at $12 \mathrm{kHz}$ ) with a $90^{\circ}$ pulse duration of $2.8 \mu$ s and a recycle delay of $10 \mathrm{~s}$. The intensity of the proton NMR signal was normalized with respect to the sample weight.

In situ diffuse reflectance infrared (DRIFT) spectra were recorded using a Brüker IFS 70 spectrometer ( $4 \mathrm{~cm}^{-1}$ resolution, 128 scans per spectrum, MCT detector). About $30 \mathrm{mg}$ of the powdered sample was loaded inside a heated crucible located in a Thermo Spectra-Tech high-temperature cell equipped with ZnSe windows and with appropriate gas inlet and outlet connections as to pass the gas flow through the catalytic bed. Spectra were recorded every 10 min during the heating up step to $723 \mathrm{~K}\left(5 \mathrm{~K} \mathrm{~min}^{-1}\right)$ under $\operatorname{Ar}\left(50 \mathrm{~mL} \mathrm{~min}{ }^{-1}\right)$, as well as during the progressive cooling down to RT. The DRIFT spectra are reported in $\log (1 / R)$ where $R$ is the relative reflectance defined as $R=I_{H A p} / I_{K B r}$ (with $K B r$ (Fluka, purity $>99.5 \%)$ spectra recorded under the same operating conditions). ${ }^{[60]}$

Temperature-programmed reactions carried out under hydrogen $\left(\mathrm{H}_{2}\right.$-TPR) were performed using a Micromeritics AutoChem 2910 apparatus equipped with a thermal conductivity detector (TCD). The sample was loaded in a quartz U-type reactor. Measurements were performed between RT and 1073 $\mathrm{K}$ under a flow of $5 \% \mathrm{H}_{2}$ in argon $\left(25 \mathrm{~mL} \mathrm{~min}^{-1}\right)$ with a heating rate of $7.5 \mathrm{~K} \mathrm{~min}^{-1}$.

\section{Ionic Conduction: sample preparation}

$0.3 \mathrm{~g}$ of the as-synthesized $\mathrm{Ca}_{10}\left(\mathrm{PO}_{4}\right)_{6-x}\left(\mathrm{VO}_{4}\right)_{x}(\mathrm{OH})_{2} \mathrm{HAp}$ powders were pressed into pellets $(\phi=13 \mathrm{~mm})$ at 5 ton $/ \mathrm{cm}^{2}$. The pellets were heated at $773 \mathrm{~K}\left(2 \mathrm{~K} \mathrm{~min}^{-1}\right)$ for $2 \mathrm{~h}$ under $\operatorname{Ar}\left(150 \mathrm{~mL} \mathrm{~min}^{-1}\right)$. The thickness of the pellets was estimated to be about $1.2 \mathrm{~mm}$. The bulk pellet density estimated from the above- 
described pellet geometry reaches $\sim 50 \%$ of the theoretical density value $\left(3.2 \mathrm{~g} \mathrm{~cm}^{-3}\right)$. Due to limited annealing temperature of the pellet, this value is rather low for conductivity measurements. However, given that the aim of the study was not to measure the intrinsic conductivity values of these materials but to discuss how ionic conductivity influences the catalytic process, this pellet density was kept.

\section{Proton Conductivity measurements}

The ionic conductivity of $\mathrm{Ca}_{10}\left(\mathrm{PO}_{4}\right)_{0.78}\left(\mathrm{VO}_{4}\right)_{5.22}(\mathrm{OH})_{2}$ was measured by $\mathrm{AC}$ impedance spectroscopy using a ProboStat ${ }^{\mathrm{TM}}$ ACIS set-up from NorECs under various dynamic atmospheres: dry or wet inert flows, pretreatment gas flow, and reacting gases. Unless otherwise stated, Pt-grids pressed against the wafer were used as electrodes. Impedance measurement was performed at 298-1073 K with stepwise increments of $50 \mathrm{~K}$ in a frequency range from 1 to $5 \times 10^{6} \mathrm{~Hz}$ with an amplitude of $100 \mathrm{mV}_{\mathrm{rms}}$ and 11 points per decade. Figure S7 shows the complex impedance plots of $\mathrm{Ca}_{10}\left(\mathrm{PO}_{4}\right)_{0.78}\left(\mathrm{VO}_{4}\right)_{5.22}(\mathrm{OH})_{2}$ measured at $1073 \mathrm{~K}$. The equivalent electrical circuit used to extract the electrical parameters was Rohm-drop in series with Rct//CPEct in series with a Warburg element. ${ }^{[61]}$ Zview software was used to analyze the spectra recorded at various temperatures. In this equivalent circuit, Rohm-drop represents the resistance of the $\mathrm{H}^{+}$-ion conducting ceramics whilst $\mathrm{RcT} / / \mathrm{CPEct}$ elements are related to the ceramic/metallic interfaces ( $\mathrm{Pt}$ or $\mathrm{Au}$ ) and the metallic electrodes. The ionic conductivity was calculated with the equation: $\sigma=I / R S$ where $/$ is the thickness of the pellet $(1.2 \mathrm{~mm}), \mathrm{S}$ is the surface of the electrode $\left(5.3 \mathrm{~cm}^{2}\right)$ and $\mathrm{R}$ is the total impedance. A first series of in situ measurements were performed under inert gas, $\operatorname{Ar}\left(\right.$ Alphagaz $1, \mathrm{H}_{2} \mathrm{O} \leq 3 \mathrm{ppm}$, Air Liquide) with a flow rate of $30 \mathrm{mLmin}^{-1}$.

\section{Catalytic reactions}

\section{$\mathrm{MBOH}$ model reaction}

The model $\mathrm{MBOH}$ gas phase reaction was carried out using a differential flow micro-reactor. The catalyst $(25 \mathrm{mg}$ ) was placed on a fritted disk in a U-type quartz reactor of $10 \mathrm{~mm}$ internal diameter. The temperature of the catalyst bed was controlled by a thermocouple located close to the wall of the quartz reactor. The samples were firstly pre-treated under a nitrogen flow $\left(20 \mathrm{~mL} \mathrm{~min}{ }^{-1}\right)$ up to $723 \mathrm{~K}$ 
$\left(5 \mathrm{~K} \mathrm{~min}^{-1}\right)$, maintained at this temperature for $120 \mathrm{~min}$ and finally cooled down to the reaction temperature of $413 \mathrm{~K}$. Then the catalyst was exposed to the reacting feed obtained by bubbling nitrogen (45 mL min ${ }^{-1}$ ) in liquid $\mathrm{MBOH}$ (Fluka, 99.9\%) at $293 \mathrm{~K} \mathrm{(MBOH}$ partial pressure of $1.73 \mathrm{kPa}$ ). Reaction products were analyzed every 2 min using a $\mu$-GC (Varian, CP 2003P) chromatograph equipped with a CPWAX 52 CB column.

\section{Propane conversion to propene in ODHP conditions}

Prior to the catalytic runs, the samples ( $0.10 \mathrm{~g}$ unless stated otherwise) were heated in $\mathrm{O}_{2}(2.1 \%)-\mathrm{He}$ $\left(11.75 \mathrm{~mL}_{\text {NTP }} \mathrm{min}^{-1}\right)$ at $773 \mathrm{~K}\left(2 \mathrm{~K} \mathrm{~min}^{-1}\right)$ for $3 \mathrm{~h}$. The temperature was then decreased to $673 \mathrm{~K}$.

The $\mathrm{C}_{3} \mathrm{H}_{8}$ conversion experiments were carried out in a U-type quartz reactor ( $10 \mathrm{~mm}$ i.d.). The samples were held on a plug of quartz wool, and the temperature was controlled by a Eurotherm 2408 temperature controller using a $\mathrm{K}$ type thermocouple. Reactant gases (Air Liquide, used as received) were fed from independent mass flow controllers (Brooks 5850TR and Bronkhorst F-201CV-200-RAD11-V). Typically, the composition of the $\mathrm{C}_{3} \mathrm{H}_{8}-\mathrm{O}_{2}-\mathrm{He}(3.5-1.0-43.1)$ reaction mixture was: $7.4 \% \mathrm{C}_{3} \mathrm{H}_{8}$ and $2.1 \% \mathrm{O}_{2}$ in $\mathrm{He}$ with a total gas flow of $12.5 \mathrm{~mL}_{\mathrm{NTP}} \mathrm{min}^{-1}$. The catalyst was contacted with the reaction mixture at $673 \mathrm{~K}$ and the temperature was increased by steps of $25 \mathrm{~K}\left(5 \mathrm{~K} \mathrm{~min}^{-1}\right)$ up to $773 \mathrm{~K}$ for about $1 \mathrm{~h} 30$ at each reaction step at atmospheric pressure. Analysis of the composition of the reactor outflow was performed on-line using a $\mu$-GC (Varian, CP4900) using three different columns running in parallel. The 5A molecular sieve column ( $353 \mathrm{~K}, 150 \mathrm{kPa} \mathrm{He}, 200 \mathrm{~ms}$ injection time, $30 \mathrm{~s}$ backflush time) was used to separate $\mathrm{H}_{2}, \mathrm{O}_{2}, \mathrm{CH}_{4}$ and $\mathrm{CO}$. The poraplot Q column ( $373 \mathrm{~K}, 150 \mathrm{kPa} \mathrm{He}$, 50 ms injection time, $6 \mathrm{~s}$ backflush time), was used to separate $\mathrm{CO}_{2}, \mathrm{C}_{2} \mathrm{H}_{4}, \mathrm{C}_{2} \mathrm{H}_{6}, \mathrm{H}_{2} \mathrm{O}, \mathrm{C}_{3} \mathrm{H}_{6}$ and $\mathrm{C}_{3} \mathrm{H}_{8}$. The CP-SIL5 column ( $318 \mathrm{~K}, 150 \mathrm{kPa} \mathrm{He}, 50$ ms injection time) was used to separate $\mathrm{C}_{3} \mathrm{H}_{6} \mathrm{O}$ compounds (acetone + propenal) from $\mathrm{C}_{3} \mathrm{H}_{4} \mathrm{O}$ (acrolein).

The conversion of $\mathrm{C}_{3} \mathrm{H}_{8}\left(\mathrm{XC}_{3} \mathrm{H}_{8}\right)$ and the product selectivities $\left(\mathrm{SA}_{i}\right)$ were calculated as follows:

$X \mathrm{C}_{3} \mathrm{H}_{8}(\%)=\left(\Sigma \mathrm{n}_{\mathrm{i}}\left[\mathrm{A}_{\mathrm{i}}\right] /\left(3 \times\left[\mathrm{C}_{3} \mathrm{H}_{8}\right]_{\text {inlet }}\right)\right) \times 100$ 
$S A_{i}(\%)=\left(n_{i}\left[A_{i}\right] / \Sigma n_{i}\left[A_{i}\right]\right) \times 100 ;$

where $n_{i},\left[A_{i}\right]$ and $\left[C_{3} H_{8}\right]_{\text {inlet }}$ are the number of carbon atoms in the $A_{i}$ products and the concentrations of the $A_{i}$ products, and the inlet concentration of propane, respectively.

Under the present experimental conditions it was checked that the reactor did not contribute to the transformation of $\mathrm{C}_{3} \mathrm{H}_{8}$ to a significant extent at $773 \mathrm{~K}$ and that both $\mathrm{C}_{3} \mathrm{H}_{8}$ and $\mathrm{O}_{2}$ conversions measured at $723 \mathrm{~K}$ varied proportionally to the amount of $\mathrm{Ca}_{10}\left(\mathrm{PO}_{4}\right)_{0.78}\left(\mathrm{VO}_{4}\right)_{5.22}(\mathrm{OH})_{2}$ loaded in the reactor indicating the absence of external limitations. The carbon and oxygen balances were found to be above 98 and $92 \%$, respectively.

\section{Operando ionic conductivity}

The set-up used for ionic conductivity measurements was slightly modified for operando measurements, connecting the inlet of the cell to the alimentation of the reacting feed and its outlet to the above described $\mu-G C$ equipment used for the catalytic measurements. The temperature profile and the composition of the pretreatment and reacting feeds used for these experiments are similar to those used for the catalytic activity measurement, except that the total flow was adjusted to keep the contact time identical to that achieved for conventional catalytic experiments. The $\mathrm{H}^{+}$ion conductivity was measured at $773 \mathrm{~K}$ during the pretreatment, then, the temperature was cooled down to $673 \mathrm{~K}$ and the conductivity set-up was fed with the reacting feed. The $\mathrm{H}^{+}$ion-conductivity of the working catalyst was measured after 2 hours on stream at 673,723 and $773 \mathrm{~K}$.

In preliminary experiments, low conversions and total oxidation of $\mathrm{C}_{3} \mathrm{H}_{8}$ in $\mathrm{CO}_{2}$ were obtained in these conditions. The different shape of the cell reactor and the use of a pellet may result in preferential pathways and be responsible for the lower conversion. Regarding the $\mathrm{C}_{3} \mathrm{H}_{6}$ selectivity, it was found that the Pt grid collector and wires greatly contribute to the total conversion into $\mathrm{CO}_{2}$. Hence, the Pt grid collector and wires were substituted by Au ones, but the presence of the Pt thermocouple could not be avoided. In this configuration, propene formation could be detected assessing that the reaction 
takes place, even though lower propene selectivity is still obtained compared to that obtained in the catalytic set-up.

Finally, in order to evaluate the role of water formed during the catalytic reaction on the conductivity measurements, additional conductivity measurements were performed at 723 and $773 \mathrm{~K}$, switching alternatively the flow from dry He (He was used in these experiments as it was the carrier gas used for pretreatment and catalytic reaction) to a wet He flow. The system was flushed with dry He for 45 min between the temperature dwells. The amounts of water introduced in $\mathrm{He}$ at 723 and $773 \mathrm{~K}$ was 1.3 and $1.6 \%$, respectively, which are similar to those produced during the catalytic reaction. Water was added by bubbling dry $\mathrm{He}$ in a water saturator maintained at 284 and $287 \mathrm{~K}$ to achieve water vapor pressures of about 1.3 and $1.6 \mathrm{kPa}$, respectively.

\section{Acknowledgements}

The authors thank the DIM OXYMORE program of the lle de France region for the financial support of Sarah Petit PhD. The authors are grateful to Vincent Lhosinho and Christophe Calers from the Laboratoire Réactivité de Surface, Sorbonne Université, for their help in the maintenance of the $\mathrm{MBOH}$ reaction set-up and the XPS measurements, respectively.

Keywords: vanadium, oxy-hydroxy-apatite, ODHP, acid-base properties, operando ionic conduction.

[1] J. C. Elliot, Structure and Chemistry of the Apatites and Other Calcium Orthophosphates., Vol. 18, Elsevier, Amsterdam, Neth., 1994.

[2] aG. Gasquières, C. Bonhomme, J. Maquet, F. Babonneau, S. Hayakawa, T. Kanaya, A. Osaka, Magn. Reson. Chem. 2008, 46, 342-346; bH. W. Kim, L. H. Li, Y. H. Koh, J. C. Knowles, H. E. Kim, J. Am. Ceram. Soc. 2004, 87, 1939-1944; cN. S. Resende, M. Nele, V. M. M. Salim, Thermochimica Acta 2006, 451, 16-21; dS. Diallo-Garcia, D. Laurencin, J. M. Krafft, S. Casale, M. E. Smith, H. Lauron-Pernot, G. Costentin, J. Phys. Chem. C 2011, 115, 24317-24327; eE. Landi, S. Sprio, M. Sandri, G. Celotti, A. Tampieri, Acta Biomater. 2008, 4, 656-663; fS. Sugiyama, T. Osaka, Y. Hirata, K. I. Sotowa, Appl. Catal. A 2006, 312, 52-58; gK. Matsunaga, J. Chem. Phys. 2008, 128, 245101- 
245110; hY. Tanaka, M. Kikuchi, K. Tanaka, K. Hashimoto, J. Hojo, M. Nakamura, A. Nagai, T. Sugiyama, F. Munakata, K. Yamashita, J. Am. Ceram. Soc., 2010, 93, 3577-3579; iL. El Hammari, A. Laghzizil, P. Barboux, A. Saoiabi, K. Lahlil, J. Solid State Chem. 2004, 177, 134-138; jE. Kramer, E. Itzkowitz, M. Wei, Ceramics International 2014, 40, 13471-13480.

[3] S. Dasgupta, S. S. Banerjee, A. Bandyopadhyay, S. Bose, Langmuir 2010, 26, 4958-4964.

[4] aM. Dapporto, S. Sprio, C. Fabbi, E. Figallo, A. Tampieri, J. Eur. Ceram. Soc. 2016, 36, 2383-2388; bS. Oh, N. Oh, M. Appleford, J. L. Ong, Am. J. Biochem. Biotech. 2006, 2, 49-56.

[5] M. Y. Ma, Y. J. Zhu, L. Li, S. W. Cao, J. Mater. Chem. 2008, 18, 2722.

[6] H. Liu, F. Chen, P. Xi, B. Chen, L. Huang, J. Cheng, C. Shao, J. Wang, D. Bai, Z. Zeng, J. Phys. Chem. C 2011, 115, 18538-18544.

[7] aP. J. Panteix, I. Julien, P. Abelard, D. Bernache-Assollant, J. Eur. Ceram. Soc. 2008, 28, 821-828; bM. Yashima, N. Kubo, K. Omoto, H. Fujimori, K. Fujii, K. Ohoyama, J. Phys. Chem. C 2014, 118, 5180-5187; cN. Horiuchi, M. Nakamura, A. Nagai, K. Katayama, K. Yamashita, J. Appl. Phys. 2012, 112, 074901-074906; dS. Nakamura, H. Takeda, K. Yamashita, J. Appl. Phys. 2001, 89, 5386.

[8] P. Perrin, O. J. F. J. G. Bodson, T. Delplanche, D. Breugelmans, Vol. PCT Int. Appl. (2015), WO 2018104446 A2 20180614., 2015.

[9] T. Delplanche, A. Gervasini, Vol. WO 2018104446 A2 20180614., WO 2018104446 A2 20180614. ed., 2018.

[10] M. Schiavoni, S. Campisi, P. Carniti, A. Gervasini, T. Delplanche, Appl. Catal. A 2018, 563, 43-53.

[11] aK. Yamaguchi, K. Mori, T. Mizugaki, K. Ebitani, K. Kaneda, J. Am. Chem. Soc. 2000, 122, 71447145; bZ. Opre, J. D. Grunwaldt, M. Maciejewski, D. Ferri, T. Mallat, A. Baiker, J. Catal. 2005, 230, 406-419; cT. Tian, Y. Liu, X. Zhang, Chinese J. Catal. 2015, 36, 1358-1364; dN. Jamwal, M. Gupta, S. Paul, Green Chem. 2008, 10, 999-1003; eZ. Opre, J. D. Grunwaldt, T. Mallat, A. Baiker, J. Mol. Catal. 2005, 242, 224-232.

[12] aS. Ogo, A. Onda, K. Yanagisawa, Appl. Catal. A 2008, 348, 129-134; bK. Kaneda, T. Hara, N. Hashimoto, T. Mitsudome, T. Mizugaki, K. Jitsukawa, Catal. Today 2010, 152, 93-98; cT. Hara, S. Kanai, K. Mori, T. Mizugaki, K. Ebitani, K. Jisukawa, K. Kaneda, J. Org. Chem. 2006, 71, 7455-7462; dY. Maeda, Y. Washitake, T. Nishimura, K. Iwai, T. Yamauchi, S. Uemura, Tetrahedron 2004, 60, 9031-9036; eV. D. B. C. Dasireddy, S. Singh, H. B. Friedrich, Appl. Catal. A 2012, 421-422, 58-69; fD. B. C. D. Venkata, B. F. Holger, S. Sooboo, Appl. Catal. A 2013, 467, 142-153; gV. D. B. C. Dasireddy, S. Singh, H. B. Friedrich, J. Mol. Catal. A 2014, 395, 398-408; hS. Singh, S. B. Jonnalagadda, Catal. Lett. 2008, 126, 200-206.

[13] aC. A. Carrero, R. Schloegl, I. E. Wachs, R. Schomaecke, ACS Catal. 2014, 4, 3357-3380; bR. Grabowski, Catal. Rev. 2006, 48, 199-268.

[14] S. Sugiyama, H. Hayashi, Int. J. Modern Phys. B 2003, 17, 1476-1481.

[15] P. Mars, D. W. Van Krevelen, Chem. Eng. Sci. 1954, 3, 41-59.

[16] aS. Barman, N. Maity, K. Bhatte, S. Ould-Chikh, O. Dachwald, C. Haeßner, Y. Saih, E. Abou-Hamad, I. Llorens, J. L. Hazemann, K. Kohler, V. D'Elia, B. J.M., ACS Catal. 2016, 6, 5908-5921; bP. Kube, 
B. Frank, S. Wrabetz, J. Krohnert, M. Havecker, J. Velasco-Velez, J. Noack, R. Schlogl, A. Trunschke, ChemCatChem 2017, 9, 573-585; cK. Chalupka, C. Thomas, Y. Millot, F. Averseng, S. Dzwigaj, J. Catal. 2013, 305, 46-55; dD. Siew Hew Sam, V. Soenen, J. C. Volta, J. Catal. 1990, 123, 417-435; eM. J. Cheng, K. Chenoweth, J. Oxgaard, A. van Duin, A. Goddard, J. Phys. Chem. C 2007, 111, 5115-5127; fA. Corma, J. M. Lopez-Nieto, N. Paredes, J. Catal. 1993, 144, 425-423.

[17] aL. Leveles, K. Seshan, J. A. Lercher, L. Lefferts, J. Catal. 2003, 218, 307-314; bX. Rozanska, R. Fortrie, J. Sauer, J. Phys. Chem. C 2007, 111, 6041-6050; cM. Zboray, A. T. Bell, E. Iglesia, J. Phys. Chem. C 2009, 113, 12380-12386.

[18] aE. A. Mamedov, V. P. Vislovskii, R. M. Talyshinskii, R. G. Rizayev, Stud. Surf. Sci. 1992, 72, $379-$ 386; bB. Grzybowska-Swierkosz, Annu. Rep. Prog. Chem., Sect. C 2000, 96, 297-334.

[19] aA. Pantazidis, A. Burrows, C. J. Kiely, C. Mirodatos, J. Catal. 1998, 177, 325-334; bM. Khachani, M. Kacimi, A. Ensuque, J. Y. Piquemal, C. Connan, F. Bozon-Verduraz, M. Ziyad, Appl. Catal. A 2010, 388, 113-123; cA. Klisinska, A. Haras, K. Samson, M. Witko, B. Grzybowska, J. Mol. Catal. A 2004, 210, 87-92.

[20] aG. Busca, E. Finocchio, G. Ramis, G. Ricchiardi, Catal. Today 1996, 32, 133-143; bL. Savary, J. Saussey, G. Costentin, M. M. Bettahar, G.-B. M., J. C. Lavalley, Catal. Today 1996, 32, 57-61.

[21] A. Klisinska, S. Loridant, B. Grzybowska, J. Stocha, I. Gressel, Appl. Catal. A 2006, 309, 17-26.

[22] aA. Venugopal, M. S. Scurrell, Appl. Catal. A 2003, 245, 137-147; bA. Hassine, S. Sebti, A. Solhy, M. Zahouily, C. Len, M. N. Hedhili, A. Fihri, Appl. Catal. A 2013, 450, 13-18; cJ. Huang, L. C. Wang, Y. M. Liu, Y. Cao, H. Y. He, K. N. Fan, Appl. Catal. B 2011, 101, 560-569; dM. I. Dominguez, F. Romero-Sarria, M. A. Centeno, J. A. Odriozola, Appl. Catal. B 2009, 87, 245-251; eK. Zhao, B. Qiao, J. Wang, Y. Zhang, T. Zhang, Chem. Commun. 2011, 47, 1779-1781.

[23] aV. D. B. C. Dasireddy, S. Singh, H. B. Friedrich, Catal. Lett. 2015, 145, 668-678; bA. Corma, J. M. Lopez-Nieto, N. Parades, M. Perez, Y. Shen, H. Cao, S. L. Suib, Stud. Surf. Sci. 1992, 72, 213-220.

[24] C. Bauer Boechat, J. G. Eon, A. Malta Rossi, C. A. de Castro Perez, R. Aguiar da Silva San Gil, Phys. Chem. Chem. Phys. 2000, 2, 4225-4230.

[25] M. Ben Osman, J. M. Krafft, Y. Millot, F. Averseng, T. Yoshioka, J. Kubo, G. Costentin, Eur. J. Inorg. Chem. 2016, 17, 2709-2720.

[26] S. Petit, T. Gode, C. Thomas, S. Dzwigaj, Y. Millot, D. Brouri, J. M. Krafft, G. Rousse, C. LabertyRobert, G. Costentin, Phys. Chem. Chem. Phys. 2017, 19, 9630-9640.

[27] aP. Alberius-Henning, E. Adolfsson, J. Grins, A. Fitch, J. Mater. Sci. 2001, 36, 663-668; bK. Yamashita, H. Owada, T. Umegaki, K. T., T. Futagami, Solid State Ionics 1988, 660-663; cJ. P. Gittings, C. R. Bowen, I. G. Turner, A. C. E. Dent, B. F.R., J. B. Chaudhuri, Mater. Sci. Forum 2008, 587-588, 91-95.

[28] aH. Lauron-Pernot, F. Luck, J. M. Popa, Appl. Catal. A 1991, 78, 213-225; bH. Lauron-Pernot, Catal. Rev. 2006, 48, 315-361.

[29] C. A. Ospina, J. Terra, A. J. Ramirez, M. Farinac, D. E. Ellis, A. M. Rossi, Colloids Surf. B Biointerf. 2012, 89, 15-22. 
[30] aM. Ben Osman, S. Diallo Garcia, J. M. Krafft, C. Methivier, J. Blanchard, T. Yoshioka, J. Kubo, G. Costentin, Phys. Chem. Chem. Phys. 2016, 18, 27837-27847; bT. Tsuchida, J. Kubo, T. Yoshioka, S. Sakuma, T. Takeguchi, W. Ueda, J. Catal. 2008, 259, 183-189; cL. Silvester, J. F. Lamonier, R. N. Vannier, C. Lamonier, M. Capron, A. S. Mamede, F. Pourpoint, A. Gervasini, F. Dumeignil, J. Mater. Chem. A 2014, 2, 11073-11090.

[31] aS. Diallo-Garcia, M. Ben Osman, J. M. Krafft, S. Boujday, G. Costentin, Catal Today 2014, 226, 81-88; bL. Bertinetti, A. Tampieri, E. Landi, G. Martra, S. Coluccia, J.Eur. Ceramic Soc. 2006, 26, 987-991.

[32] P. Concepcion, B. M. Reddy, H. Knozinger, Phys. Chem. Chem. Phys. 1999, 1.

[33] aP. Li, Y. Xiang, V. H. Grassian, S. C. Larsen, J. Phys. Chem. B 1999, 103, 5058-5062; bK. Hadjiivanov, E. Ivanova, H. Knozinger, Micropor. Mesopor. Mat. 2003, 58, 225-236.

[34] S. Dzwigaj, E. Ivanova, R. Kefirov, K. Hadjiivanov, F. Averseng, J. M. Krafft, M. Che, Catal.Today 2009, 142, 185-191.

[35] aK. Hadjiivanov, H. Knozinger, J. Phys. Chem. B 2001, 105, 4531-4534; bP. Concepcion, K. Hadjiivanov, H. Knozinger, J. Catal. 1999, 184, 172-179.

[36] S. Diallo-Garcia, M. Ben Osman, J. M. Krafft, S. Casale, C. Thomas, J. Kubo, G. Costentin, J. Phys. Chem. C 2014, 118, 12744-12757.

[37] aR. M. Wilson, J. C. Elliot, S. E. P. Dowker, J.Solid State Chem. 2003, 174, 132-140; bM. Jarlbring, D. E. Sandström, O. N. Antzutkin, W. Forsling, Langmuir 2006, 22, 4787-4792.

[38] M. Ben Osman, S. Diallo-Garcia, V. Herledan, T. Yoshioka, K. Kubo, Y. Millot, G. Costentin, J. Phys. Chem. C 2015, 119, 23008-23020.

[39] A. Onda, S. Ogo, K. Kajiyoshi, K. Yanagisawa, Mater. Lett. 2008, 62, 1406-1409.

[40] aY. Tanaka, T. Iwasaki, M. Nakamura, A. Nagai, K. Katayama, J. Appl. Phys. 2010, 107, 014107010141-014110; bA. M. Sofronia, R. Baies, A. E.M., C. A. Marinescu, S. Tanasescu, Mater. Sci. Eng. C 2014, 43, 153-163; CY. Tanaka, M. Nakamura, A. Nagai, T. Toyama, K. Yamashita, Mater. Sci. Eng. B 2009, 161, 115-119; dB. Singh, S. Kumar, B. Basu, R. Gupta, Mater. Lett. 2013, 95, 100102.

[41] K. D. Kreuer, A. Rabeneau, W. Weppner, Angew. Chem. Int. Ed. Engl. 1982, 21, 208-209.

[42] N. Horiuchi, J. Endo, N. Wada, K. Nozaki, M. Nakamura, A. Nagai, K. Katayama, K. Yamashita, J. Appl. Phys. 2013, 113, 134905-134901-134905-134905.

[43] A. Bouhaouss, A. Laghzizil, A. Bensaoud, M. Ferhat, G. Lorent, J. Livage, Int. J. Inorg. Mater. 2001, 3, 743-747.

[44] H. Suda, M. Yashima, M. Kakihana, M. Yoshimura, J. Phys. Chem. 1995, 99, 6752-6754.

[45] N. Hitmi, C. Lacabanne, R. A. Young, J. Phys. Chem. Solids 1986, 47, 533-546.

[46] aK. Yamashita, K. Kitagaki, T. Umegaki, J. Am. Ceram. Soc 1995, 78, 1191-1197; bA. Laghzizil, N. Elherch, A. Bouhaouss, G. Lorente, T. Coradin, J. Livage, Mater. Res. Bull. 2001, 36, 953-962. 
[47] aN. Horiuchi, J. Endo, K. Nozaki, M. Nakamura, A. Nagai, K. Katayama, K. Yamashita, J. Ceram. Soc. Japan 2013, 121, 770-774; bG. C. Maiti, F. Freund, J. Chem. Soc., Dalton Trans. 1981, 19721999, 949-955.

[48] M. Ben Osman, J. M. Krafft, C. Thomas, T. Yoshioka, J. Kubo, G. Costentin, ChemCatChem 2019, $11,1765-1778$.

[49] aJ. C. Vedrine, Topics Catal. 2002, 21, 97-106; bA. Pantazidis, A. Auroux, H. J.M., C. Mirodatos, Catal. Today 1996, 32, 81-88.

[50] Y. Zhang, R. P. A. Sneeden, J. C. Volta, Catal. Today 1993, 16, 39-49.

[51] aL. Thomas, R. Tanner, P. Gill, R. Wells, J. E. Bailie, G. Kelly, JacksonS.D., G. Hutchings, Phys. Chem. Chem. Phys. 2002, 4, 4555-4560; bV. A. Zazhigalov, Kinet. Catal. 2002, 43, 514-521.

[52] aJ. F. Groust, G. Costentin, K. J.M., P. Massiani, Phys. Chem. Chem. Phys. 2010, 12, 937-946; bC. Drouilly, J. M. Krafft, F. Averseng, H. Lauron-Pernot, D. Bazer-Bachi, C. Chizallet, V. Lecocq, G. Costentin, Catal. Today 2013, 205, 67-75.

[53] aM. Jin, Z. M. Cheng, Catal. Lett. 2009, 131, 266-278; bE. K. Lee, K. D. Jung, O. S. Joo, Y. G. Shul, Catal. Lett. 2004, 98, 259-263; cR. Baran, T. Onfroy, T. Grzybek, S. Dzwigaj, Appl. Catal. B Env. 2013, 136-137, 186-192.

[54] D. Stošić, S. Bennici, S. Sirotin, C. Calais, J. L. Couturier, J. L. Dubois, A. Travert, A. Auroux, Appl. Catal. A 2012, 447-448, 124-134.

[55] aV. Soenen, J. M. Herrmann, J. C. Volta, J. Catal. 1996, 159, 410-417; bS. Sugiyama, T. Hashimoto, Y. Morishita, N. Shigemoto, H. Hayashi, Appl. Catal. A 2004, 270, 253-260.

[56] M. A. Chaar, D. Patel, H. H. Kung, J. Catal. 1988, 109, 463-467.

[57] J. C. Vedrine, Appl. Catal. A 2019, 575, 170-179.

[58] aL. Cheng, G. A. Ferguson, S. A. Zygmunt, L. A. Curtiss, J. Catal. 2013, 302, 31-36; bJ. C. Vedrine, J. M. M. Millet, J. C. Volta, Catal. Today 1996, 32, 115-123.

[59] X. Gao, P. Ruiz, Q. Xin, X. Guo, B. Delmon, Catal. Lett. 1994, 23, 321-337.

[60] J. Sirita, P. S., F. C. Meunier, Anal. Chem., 2007, 79, 3912-3918.

[61] E. Barsoukov, J. R. Macdonald, J. Am. Chem. Soc. 2005, 127, 12431. 
Synergistic effect between

propane activation and

proton conduction

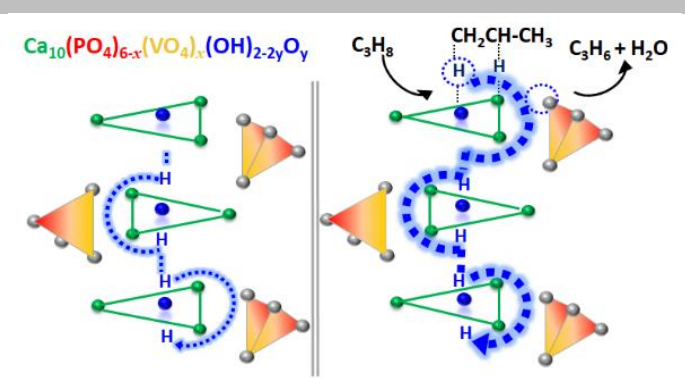

Sarah Petit, Cyril Thomas,

Yannick Millot, Jean-Marc Krafft, Christel LabertyRobert, Guylène Costentin *

Page No. - Page No.

Activation of $\mathrm{C}-\mathrm{H}$ Bond of Propane by Strong Basic Sites Generated by Bulk Proton Conduction on V-Modified Hydroxyapatites for the Formation of Propene. 
Supporting information

Activation of C-H Bond of Propane by Strong Basic Sites Generated by Bulk Proton Conduction on VModified Hydroxyapatites for the Formation of Propene.

Sarah Petit, ${ }^{a, b}$ Cyril Thomas, ${ }^{a}$ Yannick Millot, ${ }^{a}$ Jean-Marc Krafft, ${ }^{a}$ Christel Laberty-Robert, ${ }^{b}$ Guylène Costentin ${ }^{\mathrm{a}, *}$

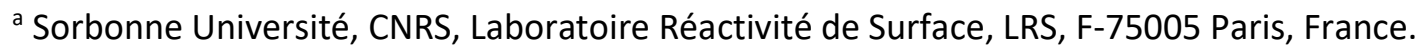

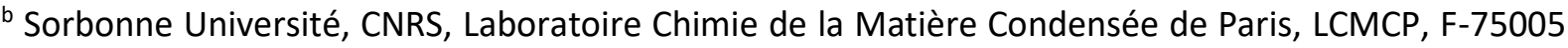
Paris, France. 
Supplementary information S1: impact of $\mathrm{CO}$ adsorption on surface acidic $\mathrm{O}-\mathrm{H}$ vibrators.

Besides the main band ascribed to structural $\mathrm{OH}$ running along the $c$ axis ( 3570 to $3550 \mathrm{~cm}^{-1}$ depending on the vanadium content), weak bands related to terminated $\mathrm{PO}-\mathrm{H}$ contributions $\mathrm{s}^{[1]}$ are observed in the V-modified samples $(x=0,3,5.2)$, as exemplified in Figure S1a in the case of $x=0$. In the case of vanadium-rich samples $(x=5.22$ and 6$)$, additional contributions of weak intensity are observed at 3627 and $3496 \mathrm{~cm}^{-1}$ (Figure S1b for $x=6$ ) that might be attributed to $v$ VO-H vibrators. ${ }^{[2]}$ As illustrated for the samples with $x=0$ and 3 in Figure S1c, CO adsorption at $100 \mathrm{~K}$ results in the perturbation of the surface PO-H groups. This clearly shows that, even in presence of vanadium in the bulk composition, some $\mathrm{Br} \not$ nsted acidic PO-H groups remain accessible on the top surface. For the V-HAp sample with $x$ $=5.22$, due to the much lower extinction coefficients of the $\mathrm{vPO}-\mathrm{H}$ contributions compared to those of the $v C O$ contributions, the perturbation of the residual $v \mathrm{PO}-\mathrm{H}$ contribution of very low intensity is more difficult to assess (not shown). As far as the sample with $x=6$ is concerned, no perturbation of the $\mathrm{VVO}-\mathrm{H}$ contributions is detected (Figure S1d), which indicates that the $\mathrm{VO}-\mathrm{H}$ species are not accessible on the top surface. 

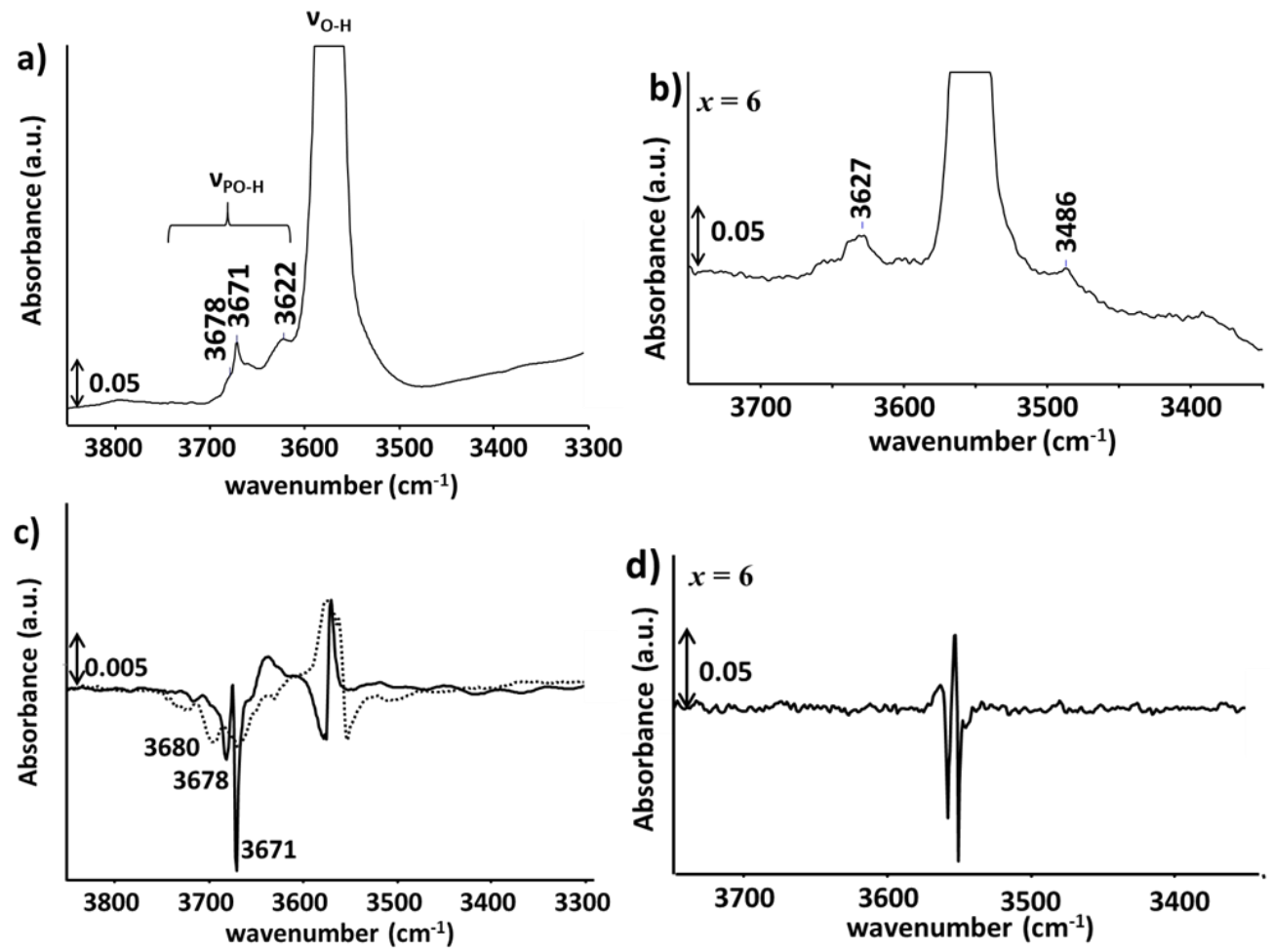

Figure S1: $\mathrm{vO}-\mathrm{H}$ area of the FTIR spectra recorded at $100 \mathrm{~K}$ after the activation under $\mathrm{O}_{2}$ at $723 \mathrm{~K}$ for $x$ $=0(\mathrm{a})$ and 6 (b) samples and difference spectra in the same area after subsequent adsorption of $\mathrm{CO}$ for $x=0$ (c, full line), $x=3$ (c, dash line) and for $x=6$ (d). 
a $1 / \mathrm{T}\left(\mathrm{K}^{-1}\right)$

1.5E-03 2.0E-03 2.5E-03 3.0E-03 3.5E-03

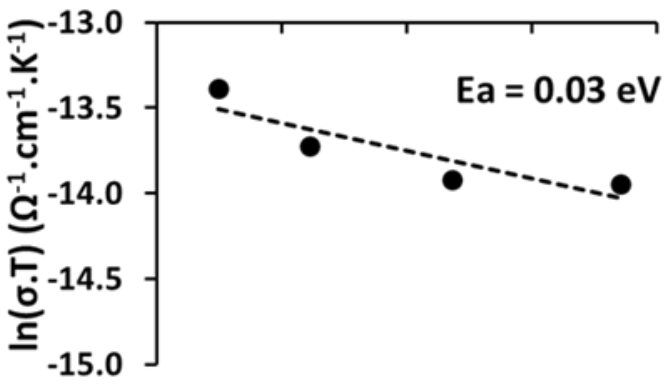

$1 / \mathrm{T}\left(\mathrm{K}^{-1}\right)$

b $\quad 1.1 \mathrm{E}-03 \quad 1.2 \mathrm{E}-03 \quad 1.3 \mathrm{E}-03 \quad 1.4 \mathrm{E}-03 \quad 1.5 \mathrm{E}-03$

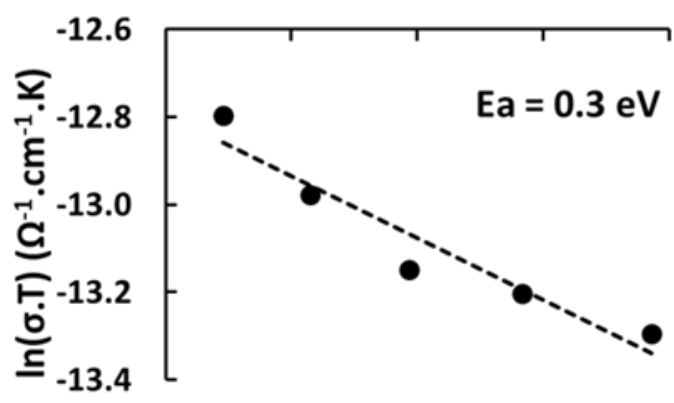

\begin{tabular}{llll}
\multicolumn{5}{c}{$1 / \mathrm{T}\left(\mathrm{K}^{-1}\right)$} \\
$6.0 \mathrm{E}-04$ & $8.0 \mathrm{E}-04$ & $1.0 \mathrm{E}-03$ & $1.2 \mathrm{E}-03$
\end{tabular}

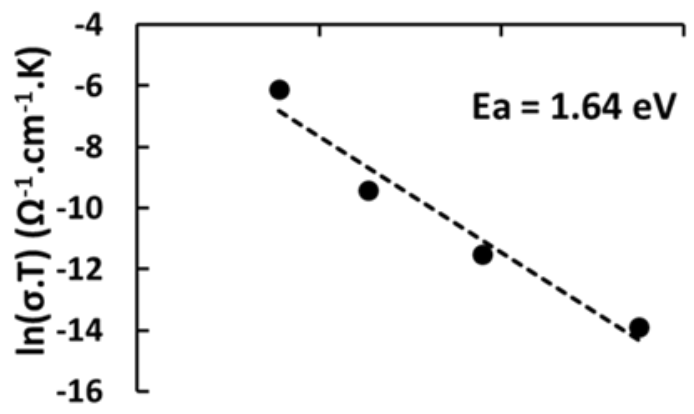

Figure S2: Arrhenius plots of the ionic conductivity of $\mathrm{Ca}_{10}\left(\mathrm{PO}_{4}\right)_{0.78}\left(\mathrm{VO}_{4}\right)_{5.22}(\mathrm{OH})_{1.32} \mathrm{O}_{0.34}$ for the a) low, b) intermediate and c) high temperature domains. 


\section{Supplementary information S3 : reactivity toward hydrogen}

In order to explain the TCD signal observed in the low temperature range even in the absence of vanadium in the HAp sample, an additional $\mathrm{H}_{2}$-TPR experiment was performed in which the outlet gas composition was monitored by mass spectrometry (RGA100, SRS, USA). The $\mathrm{m} / \mathrm{z}$ values monitored were 2,18 and 44 for $\mathrm{H}_{2}, \mathrm{H}_{2} \mathrm{O}$ and $\mathrm{CO}_{2}$, respectively.

From the data obatined for a $\mathrm{Ca}_{10}\left(\mathrm{PO}_{4}\right)_{6}(\mathrm{OH})_{2}$ sample (Figure S3a), we do confirm that the TCD signal observed in the $773-1073 \mathrm{~K}$ range is associated with $\mathrm{H}_{2}$ consumption. Water is also detected, which is consistent with the dehydration process occurring along the $\mathrm{OH}$ columns as described in the DRIFT section. $\mathrm{CO}_{2}$ is observed in minor amount essentially up to $873 \mathrm{~K}$, which indicates that this species is not responsible for the main TCD signal recorded at greater temperatures.

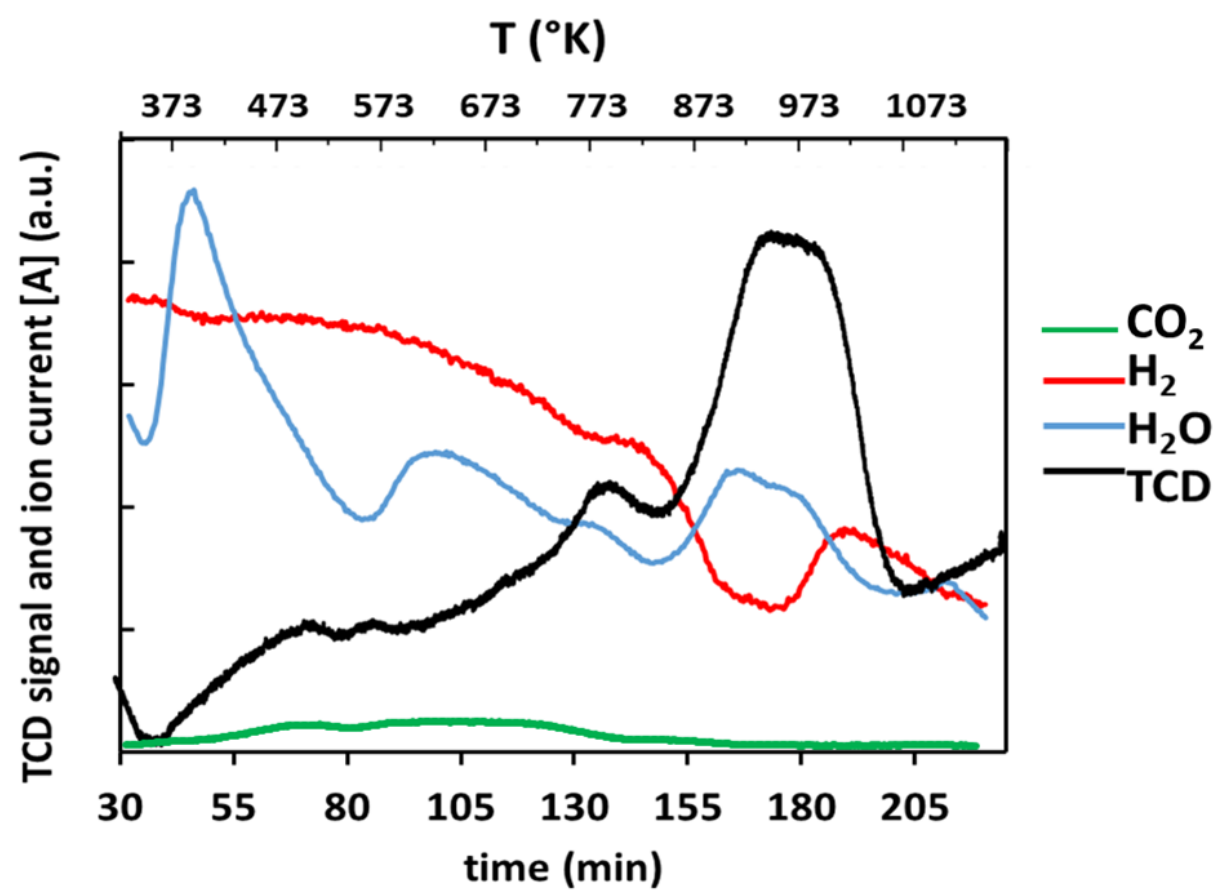

Figure S3a: TCD signal recorded during the $\mathrm{H}_{2}$-TPR experiment for $\mathrm{Ca}_{10}\left(\mathrm{PO}_{4}\right)_{6}(\mathrm{OH})_{2}$ sample and on-line analysis of gas outlet composition by mass spectrometry: $\mathrm{m} / \mathrm{z}=2\left(\mathrm{H}_{2}\right), 18\left(\mathrm{H}_{2} \mathrm{O}\right)$ and $44\left(\mathrm{CO}_{2}\right)$ signals

Complementary data were obtained by probing the surface upon thermal activation under $\mathrm{H}_{2} / \mathrm{Ar}$ flow by in situ DRIFT. The DRIFT set-up already described in the experimental section was used to follow 
the interaction of the surface with $\mathrm{H}_{2}\left(30 \mathrm{~mL} \mathrm{~min}^{-1}, 5 \% \mathrm{H}_{2}\right.$ in $\left.\mathrm{Ar}\right)$ upon heating up to $723 \mathrm{~K}$. The obtained difference DRIFT spectrum is reported in $\log \left(1 / R^{\prime}\right)$ with the relative reflectance $R^{\prime}=I_{\text {HAp } \downarrow} / I_{\text {HAp }} \uparrow$ (spectrum recorded at $423 \mathrm{~K}$ during the cooling step / spectrum recorded at $423 \mathrm{~K}$ during the temperature raising step, respectively).

Given the thermal limitations of the experimental set-up in the presence of $\mathrm{H}_{2}$ in the flow, exposure of the $\mathrm{Ca}_{10}\left(\mathrm{VO}_{4}\right)_{6}(\mathrm{OH})_{2}$ sample to hydrogen was perfomed up to $723 \mathrm{~K}$ only. The difference spectrum recorded at $423 \mathrm{~K}$ after exposure to $\mathrm{H}_{2}$ at $723 \mathrm{~K}$ shows a new contribution at $2174 \mathrm{~cm}^{-1}$ (Figure $\mathbf{S 3 b}$ ).

Earlier studies have reported on $\mathrm{Mg}-\mathrm{H}$ contributions in the 1030 to $1125 \mathrm{~cm}^{-1}$ range, $^{[3]}\left(1125 \mathrm{~cm}^{-1}\right.$ being reported for hydride species stabilized on 3-fold $\mathrm{Mg}^{2+}$ cations sites upon $\mathrm{H}_{2}$ dissociation). ${ }^{[\mathrm{cc}]}$ By analogy, $v \mathrm{Ca}-\mathrm{H}$ contributions are thus expected to be observed in the $1000-1200 \mathrm{~cm}^{-1}$ region. In the present study, due to the saturation of the structural $v \mathrm{~V}-\mathrm{O}$ bands on $\mathrm{Ca}_{10}\left(\mathrm{VO}_{4}\right)_{6}(\mathrm{OH})_{2}\left(1000-1100 \mathrm{~cm}^{-1}\right)$, this region can not be probed. The contribution observed at $2174 \mathrm{~cm}^{-1}$ on the difference spectrum (Figure S3b) can be assigned to the combination modes of vibration expected for calcium hydride vibrators. This result strongly supports the occurrence of the dissociation of $\mathrm{H}_{2}$ over the considered surface.

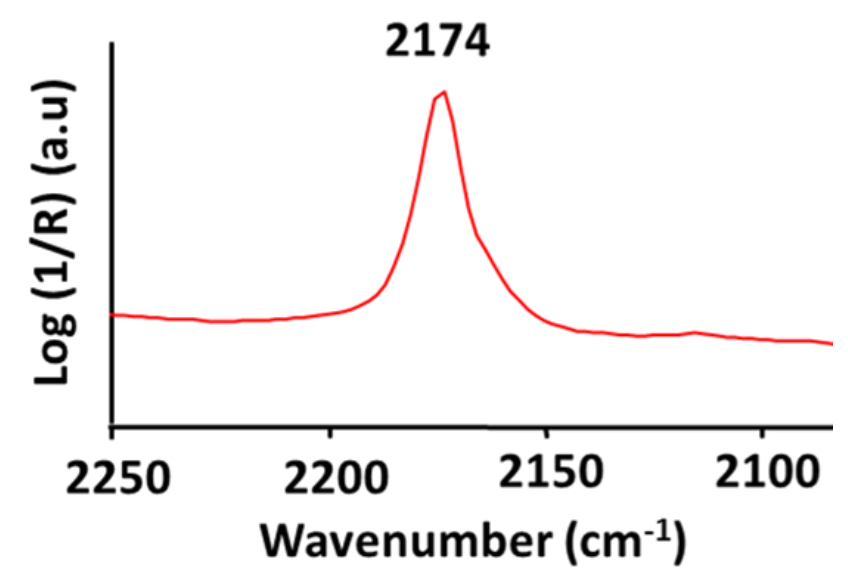

Figure S3b: difference DRIFT spectrum of $\mathrm{Ca}_{10}\left(\mathrm{VO}_{4}\right)_{6}(\mathrm{OH})_{2}$ sample recorded at $423 \mathrm{~K}$ after exposure to $\mathrm{H}_{2} / \mathrm{Ar}$ flow $\left(30 \mathrm{~mL} \mathrm{~min}^{-1}\right)$ at $723 \mathrm{~K}$. 
Supplementary information S4:Influence of the reaction temperature on the propene selectivity.

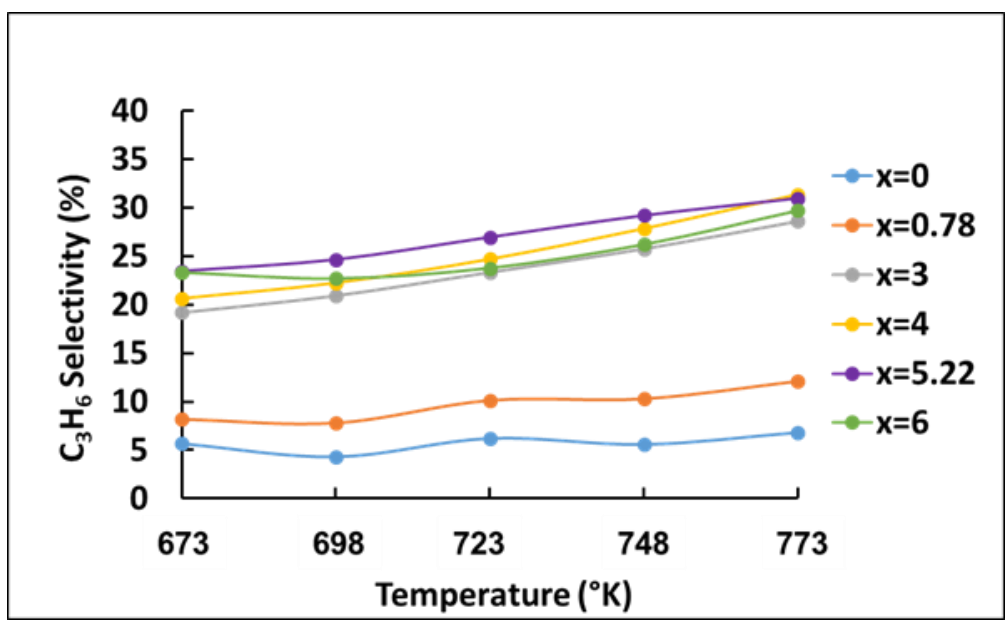

Figure S4: Influence of the reaction temperature on the propene selectivity for the $\mathrm{Ca}_{10}\left(\mathrm{PO}_{4}\right)_{6}$ ${ }_{x}\left(\mathrm{VO}_{4}\right)_{x}(\mathrm{OH})_{2-2 y} \mathrm{O}_{y}$ series of samples. 
Supplementary information $\mathrm{S} 5:$ Influence of $\mathrm{O}_{2}$ removal from the reacting feed on the catalytic propane conversion.

The $\mathrm{Ca}_{10}\left(\mathrm{PO}_{4}\right)_{0.78}\left(\mathrm{VO}_{4}\right)_{5.22}(\mathrm{OH})_{1.32} \mathrm{O}_{0.34}$ sample $(97.8 \mathrm{mg})$ was calcined under $\mathrm{O}_{2}(\sim 2 \%) / \mathrm{He}$ for $3 \mathrm{~h}$ at 500 ${ }^{\circ} \mathrm{C}\left(2{ }^{\circ} \mathrm{C} / \mathrm{min}\right.$ heating rate) before the temperature was decreased to $673 \mathrm{~K}$ under the same oxidizing mixture. The reactor was then by-passed and the $\mathrm{C}_{3} \mathrm{H}_{8}(8.2 \%)-\mathrm{O}_{2}(2.2 \%)$-He reacting mixture was made. The catalyst was then exposed to this reacting mixture at $673 \mathrm{~K}$ and $698 \mathrm{~K}$ for $1.5 \mathrm{~h}$ and at $723 \mathrm{~K}$ for about $4 \mathrm{~h}$ (Figure S5). The conversion of $\mathrm{C}_{3} \mathrm{H}_{8}\left(\mathrm{X} \mathrm{C}_{3} \mathrm{H}_{8}\right)$ and the selectivity in $\mathrm{C}_{3} \mathrm{H}_{6}\left(\mathrm{~S}_{\mathrm{C} 3 \mathrm{H}}\right)$ are in very good accordance with the data reported in Figure 11. As reported in Table S5, the concentration in $\mathrm{H}_{2}$ remains lower than that in propene. After about $4 \mathrm{~h}$ on stream at $723 \mathrm{~K}$, the $\mathrm{O}_{2}$ flow was stopped. In the absence of significant amount of $\mathrm{O}_{2}$ in the feed, the formation of $\mathrm{C}_{3} \mathrm{H}_{6}$ was found to be divided by a factor of about 6 indicating that the corresponding formation of $\mathrm{C}_{3} \mathrm{H}_{6}$ in the presence of $\mathrm{O}_{2}$ in the feed cannot be exclusively attributed to $\mathrm{C}_{3} \mathrm{H}_{8}$ dehydrogenation. When $\mathrm{O}_{2}$ was introduced in the reacting feed, the activity of the catalyst was restored with values close to those found before the removal of $\mathrm{O}_{2}$ from the reacting feed. 
Table S5. Concentrations in $\mathrm{C}_{3} \mathrm{H}_{6}$ and $\mathrm{H}_{2}$ and corresponding conversion of $\mathrm{C}_{3} \mathrm{H}_{8}\left(\mathrm{X}_{\mathrm{C} 3 \mathrm{H}}\right)$ and the selectivity in $\mathrm{C}_{3} \mathrm{H}_{6}\left(\mathrm{~S}_{\mathrm{C}_{3} \mathrm{H}_{6}}\right)$ measured during the catalytic conversion of propane in the presence or absence (grey line) of $\mathrm{O}_{2}$ in the feed on $97.8 \mathrm{mg}$ for $\mathrm{Ca}_{10}\left(\mathrm{PO}_{4}\right)_{0.78}\left(\mathrm{VO}_{4}\right)_{5.22}(\mathrm{OH})_{1.32} \mathrm{O}_{0.34}$.

\begin{tabular}{llcll}
\hline $\mathrm{T}(\mathrm{K})$ & $\mathrm{C}_{3} \mathrm{H}_{6}$ & $\mathrm{H}_{2}(\mathrm{ppm})$ & $\mathrm{X}_{\mathrm{C3H8}}(\%)^{*}$ & $\mathrm{~S}_{\mathrm{C} 3 \mathrm{H} 6}(\%)$ \\
& $(\mathrm{ppm})$ & & & \\
& & & & \\
\hline By-Pass & 3 & 0 & 0 & 0 \\
673 & 187 & 87 & 0.9 & 24 \\
698 & 320 & 221 & 1.6 & 24 \\
723 & 578 & 458 & 2.6 & 27 \\
723 & 102 & 0 & 0.2 & 64 \\
723 & 613 & 465 & 2.8 & 27
\end{tabular}

*the reported values have been normalized with respect to the specific surface area of the $\mathrm{V}$-free sample $\mathrm{Ca}_{10}\left(\mathrm{PO}_{4}\right)_{6}\left(\mathrm{VO}_{4}\right)_{0}(\mathrm{OH})_{2}: 35 \mathrm{~m}^{2} \mathrm{~g}^{-1}$

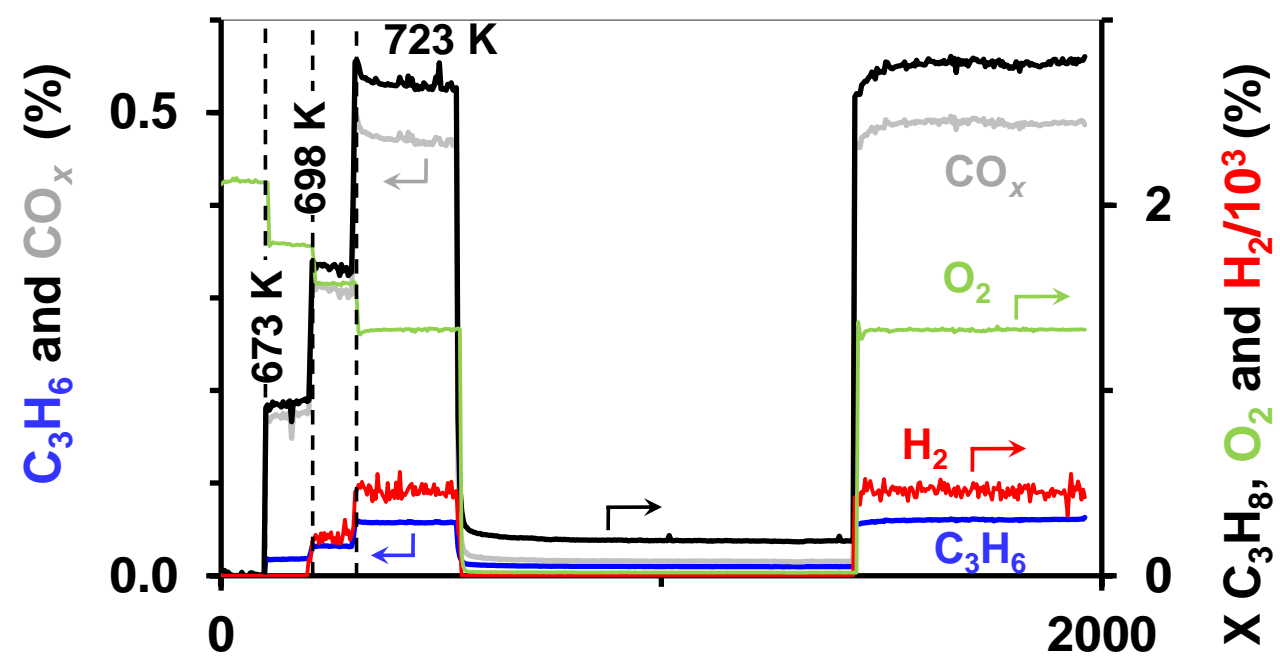

Time on stream (min)

Figure S5: Concentrations in $\mathrm{C}_{3} \mathrm{H}_{6}, \mathrm{O}_{2}, \mathrm{CO}_{x}, \mathrm{H}_{2}$ and the conversion of $\mathrm{C}_{3} \mathrm{H}_{8}\left(\mathrm{X}_{\mathrm{C} 3 \mathrm{H} 8}\right)$ in the presence and in the absence of $\mathrm{O}_{2}$ in the feed on $97.8 \mathrm{mg}$ of $\mathrm{Ca}_{10}\left(\mathrm{PO}_{4}\right)_{0.78}\left(\mathrm{VO}_{4}\right)_{5.22}(\mathrm{OH})_{1.32} \mathrm{O}_{0.34}$ 


\section{Supplementary Information S6: Processing of the complex impedance diagram}

Plot of the real $Z^{\prime}(\Omega)$ and imaginary $Z^{\prime \prime}(\Omega)$ impedance components is shown in Figure $\mathbf{S 6}$. The complex impedance diagram exhibits a semi-circle and the bulk resistance was deduced from the intersection of the semi-circle with the real axis.

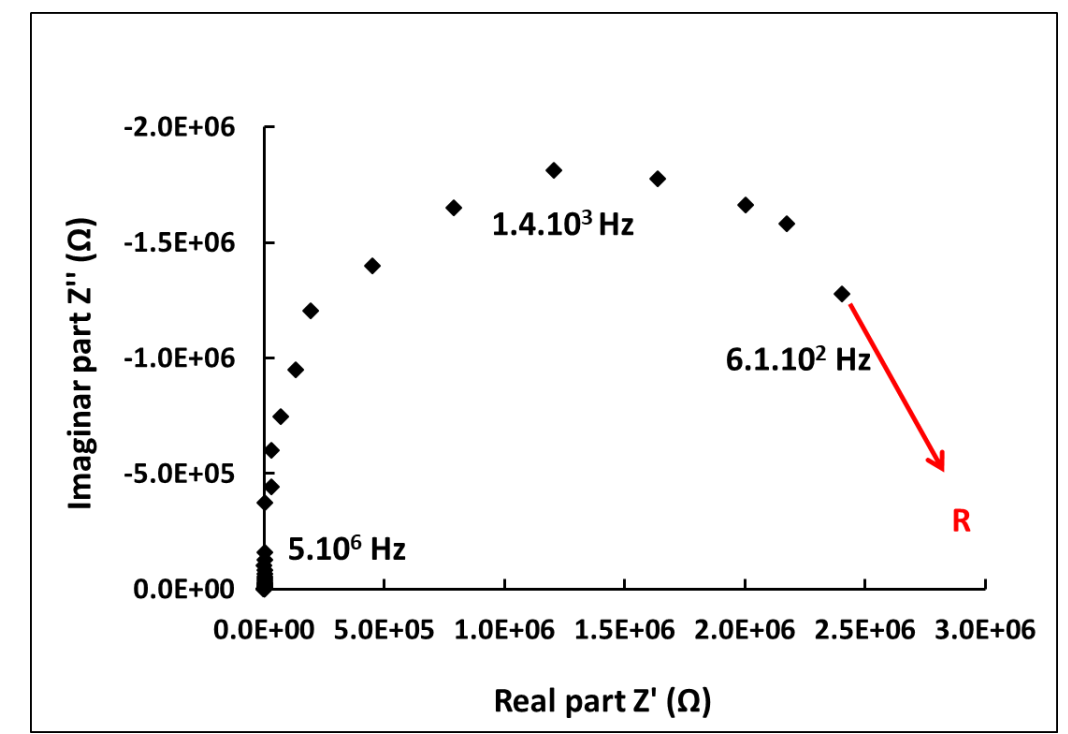

Figure S6 : Nyquist Plot for $\mathrm{Ca}_{10}\left(\mathrm{PO}_{4}\right)_{0.78}\left(\mathrm{VO}_{4}\right)_{5.22}(\mathrm{OH})_{2}$ at $1073 \mathrm{~K}$

References

[1] aS. Diallo-Garcia, M. Ben Osman, J. M. Krafft, S. Boujday, G. Costentin, Catal Today 2014, 226, 8188; bS. Diallo-Garcia, M. Ben Osman, J. M. Krafft, S. Casale, C. Thomas, J. Kubo, G. Costentin, J. Phys. Chem. C 2014, 118, 12744-12757.

[2] S. Dzwigaj, E. Ivanova, R. Kefirov, K. Hadjiivanov, F. Averseng, J. M. Krafft, M. Che, Catal.Today 2009, 142, 185-191.

[3] aF. Haque, F. Finocchi, S. Chenot, J. Jupille, S. Stankic, J. Phys. Chem. C 2018, 122, 17738-17747; bE. Knozinger, K. H. Jacob, P. Hofmann, J. Chem. Soc. Faraday Trans. 1993, 89, 1101-1107; cX. Wang, L. Andrews, J. Phys. Chem. A 2004, 108, 11511-11520. 